\title{
ANIMAL MODELS IN CRAVING RESEARCH
}

\section{The psychology and neurobiology of addiction: an incentive-sensitization view}

\author{
TERRY E. ROBINSON \& KENT C. BERRIDGE
}

Department of Psychology (Biopsychology Program), The University of Michigan, Ann Arbor, MI, USA

\begin{abstract}
The question of addiction specifically concerns (1), the process by which drug-taking behavior, in certain individuals, evolves into compulsive patterns of drug-seeking and drug-taking behavior that take place at the expense of most other activities and (2), the inability to cease drug-taking; the problem of relapse. In this paper current biopsychological views of addiction are critically evaluated in light of the "incentivesensitization theory of addiction", which we first proposed in 1993, and new developments in research are incorporated. We argue that traditional negative reinforcement, positive reinforcement, and hedonic accounts of addiction are neither necessary nor sufficient to account for compulsive patterns of drug-seeking and drug-taking behavior. Four major tenets of the incentive-sensitization view are discussed. These are: (1) Potentially addictive drugs share the ability to produce long-lasting adaptations in neural systems.

(2) The brain systems that are changed include those normally involved in the process of incentive motivation and reward. (3) The critical neuroadaptations for addiction render these brain reward systems hypersensitive ("sensitized") to drugs and drug-associated stimuli. (4) The brain systems that are sensitized do not mediate the pleasurable or euphoric effects of drugs (drug "liking"), but instead they mediate a subcomponent of reward we have termed incentive salience (drug "wanting"). We also discuss the role that mesolimbic dopamine systems play in reward, evidence that neural sensitization happens in humans, and the implications of incentive-sensitization for the development of therapies in the treatment of addiction.
\end{abstract}

\section{Introduction}

In thinking about the problem of addiction, and the development of animal models of addiction, it is important to remember that at some time many people experiment with a variety of potentially addictive drugs, but most do not become addicted. ${ }^{1}$ In other words, mere selfadministration of a drug, by a human or by a non-human animal, is not tantamount to addic- tion. ${ }^{2}$ Indeed, the factors responsible for experimental or casual drug use may or may not be directly relevant to the problem of addiction. Drug-seeking and drug-taking in the addict may involve factors that are qualitatively different from those that motivate drug-taking in the nonaddict. The question of addiction specifically concerns (a) the process by which drug-taking behavior, in certain individuals, evolves into

Correspondence to: Dr Terry E. Robinson, Department of Psychology (Biopsychology Program), The University of Michigan, 525 E. University (East Hall), Ann Arbor, MI 48109, USA. Tel: (734) 763 4361; fax: (734) 7637480 ; e-mail: ter@umich.edu

Submitted 1st September 1999; initial review completed 16th November 1999; final version accepted 10th March 2000 . 
compulsive patterns of drug-seeking and drugtaking behavior that take place at the expense of most other activities, and (b) the inability to cease drug-taking, that is, the problem of relapse. ${ }^{2}$ The purpose of this paper is to explore one view of the psychological and neurobiological mechanisms responsible specifically for the development of compulsive patterns of drug use that define addiction, and to update our earlier treatise on this subject. ${ }^{3}$

\section{Negative and positive reinforcement models}

Most contemporary explanations of addiction suggest that addicts are motivated to take drugs (crave drugs) for one of two reasons. As put by Markou et al., " "Drug craving is characterized by both the desire to experience the positive hedonic effects of the drug ... and the desire to avoid aversive withdrawal symptoms..." (p. 176). That is, it is generally thought that addicts are motivated to take drugs either for the pleasure drugs produce (basically to achieve remembered pleasure), or to avoid the unpleasant consequences of withdrawal. Some authors place the weight of explanatory burden on the aversive consequences of discontinuing drug use (the withdrawal syndrome), and thus on the action of drugs as negative reinforcers. ${ }^{2,5-7}$ For example, Koob and colleagues ${ }^{8-10}$ have argued that: "the motivation for maintenance of compulsive drug use requires negative reinforcement processes ..." (Koob et al., ${ }^{9}$ p. 519, italics added) and that, "From a motivational perspective, addiction can be equated with the development of a negative affect" (Koob, ${ }^{11}$ p. 13).

\section{Limitations of negative reinforcement models}

Despite the intuitive appeal of withdrawal avoidance models many authors have pointed out the short-comings of negative reinforcement models in general as explanations for addiction.,12-15 For example, drugs that do not produce strong withdrawal syndromes, such as psychostimulants, can be highly addictive. Conversely, there are drugs that produce tolerance and withdrawal syndromes but do not support compulsive patterns of use. The latter compounds include some tricyclic antidepressants, anticholinergics and kappa opioid agonists. ${ }^{14}$ Thus, as put by Jaffe, ${ }^{14}$ "there is little correlation between the visibility or physiological seriousness of withdrawal signs and their motivational force" (p. 9). Another problem for withdrawal-based explanations is that drug craving is often elicited by drug administration itself, in association with euphorigenic effects, at the moments when withdrawal symptoms should be at their weakest. Similarly, in animals trained to self-administer heroin, reinstatement of drug-taking behavior following extinction is more potently elicited by a priming injection of heroin, which elicits a drug-like effect, than by the injection of an opioid antagonist, which induces withdrawal signs. ${ }^{16,17}$ For human addicts, the prolonged cessation of drug use, during which time withdrawal symptoms decay, is by no means a guarantee of a cure, as relapse to compulsive use even long after withdrawal is over remains a major problem in addiction. ${ }^{18}$ In conclusion, although there is no doubt that under some circumstances the desire to avoid withdrawal can be a potent motive for drug use, for these and other reasons many authors have suggested that models of addiction based on the alleviation of withdrawal symptoms (whether "physical" or "psychological") are neither necessary nor sufficient to explain compulsive drug-seeking and drug-taking behavior. ${ }^{3,14,15}$

\section{Limitations of behaviorist positive reinforcement models}

In part because of the shortcomings of negative reinforcement models alternative models have placed considerable emphasis on the action of drugs as positive reinforcers. ${ }^{14}$ Positive reinforcers are stimuli that have the property of increasing the probability of behaviors that immediately precede their presentation. Like many natural rewards, such as food and water, potentially addictive drugs have this property. In the drug abuse literature, however, the Skinnerian concept of positive reinforcement is often invoked, either implicitly or explicitly, as though it were an explanation of drug-taking behavior, and even as an explanation of why drug-taking behavior becomes more and more compulsive in the development of addiction. (Why do people take drugs? Because drugs are positive reinforcers.) But this is a confusion. It is equivalent to saying that the reason people take drugs is because drugs promote drug-taking behavior; the circularity is obvious. ${ }^{15}$ It is important to remem- 
ber that positive reinforcement, taken as a behaviorist concept, is only a description of a behavioral effect, not an explanation of the effect (Berridge \& Robinson, ${ }^{19}$ see footnote 3 for detailed discussion). In defining reinforcement Skinner himself ${ }^{20}$ said, "The only defining characteristic of a reinforcing stimulus is that it reinforces", and argued that, "there is nothing circular about classifying events in terms of their effects ...". But he also said, "It would be circular, however, if we then went on to assert that a given event strengthens an operant because it is reinforcing" (his italics, pp. 72-3). Or, as put so well by Dews, ${ }^{21}$ “... many things can reinforce and many things can be maintained by reinforcement; which is fine, of course, provided that we do not come to suppose that in demonstrating that an event is a reinforcer we have demonstrated something more than that the event is a reinforcer". "Any worker studying behavioral phenomena knows that a reinforcer is defined and recognized through its effects on behavior; the sole criteria are behavioral. But any impartial observer of the same workers will see that teleology, like hope, springs eternal in even a scientific worker's breast" (p. 77). In other words, behaviorist reinforcement should not be mistaken to be an explanation of either drug-taking or addiction in either a physiological or psychological sense. The critical question relevant for addiction is, what explains it. That is, what effect of a drug is responsible for its positively reinforcing behavioral property, and how does it cause the development of compulsive drug-seeking and drug-taking habits?

Wise \& Bozarth ${ }^{15}$ suggested that, "the only existing positive reinforcement view of addiction that can qualify as an explanatory theory identifies positive reinforcement with drug euphoria" (p. 474). In this view (hedonia view) drugs are addicting because they produce positive affective states that people label with words such as pleasure or euphoria, and these states are what addicts seek. This pleasure-seeking view of addiction is the simple common-sense view of addiction. People want drugs (are motivated to seek and take drugs) because they like drugs (because drugs give pleasure). In this view the motivation to take drugs (drug wanting) is directly attributable to the ability of drugs to produce pleasure, i.e. there is a necessary causal relationship between wanting drugs and liking drugs.
Limitations of drug pleasure (hedonic reinforcement) models

It is probably true that often people are initially motivated to take drugs because of the ability of drugs to produce positive affective states (and because their peers are doing it, and for many other complicated psychosocial reasons), but in the addict the association between the hedonic consequences of drug consumption and the ability of drugs and drug-related stimuli to motivate behavior often become dissociated, revealing that the relationship between the motivational force of drugs and their hedonic consequences may not be a necessary causal relationship. As Dews ${ }^{21}$ cautioned many years ago, “... it was supposed that the prediction of addiction liability was essentially equivalent to prediction of euphorigenic power. As with most self-evident ideas, the mere matter of there being essentially no evidence in favor of it, and much against it, had little effect on its acceptance" (p. 75).

Perhaps the most compelling evidence against the idea that the ability of drugs to promote drug-taking is directly attributable to their subjective pleasurable effects comes from studies showing that subjective states are often poorly correlated with drug-taking. First, drug-taking may increase dramatically over time as an addiction develops, but the pleasure induced by a given dose of a drug is not reported to increase (see note 5 in Robinson \& Berridge ${ }^{3}$ for a discussion of this point). If addicts craved drugs in proportion to their ability to produce pleasure, then craving late in addiction ought not to be stronger then craving after the initial drug experience-but of course that is not the case.

Secondly, after pharmacological manipulations there is often a dissociation between the reported subjective effects of cocaine and cocaine-taking behavior. ${ }^{2-27}$ For example, Haney et $a .^{26}$ reported recently that pergolide decreased cocaine's cardiovascular effects, decreased ratings of its subjective effects ("high", "stimulated"), increased ratings of "I want cocaine", while having no effect whatsoever on cocaine self-administration behavior. Similarly, Haney et al. ${ }^{27}$ reported: "that even a $50 \%$ decrease in certain of cocaine's subjective effects by ABT-431 ... did not shift cocaine self-administration" (p. 108). Along the same lines, Comer et $a l .{ }^{28}$ reported that doses of intranasal and intravenous heroin that maintained the same "breakpoint" on a progressive ratio schedule re- 
sulted in very different subjective ratings of "high".

Thirdly, it has been reported that people will work for low doses of morphine or cocaine that produce no subjective pleasure at all; doses that indeed produce no reported subjective effects of any kind. ${ }^{22,24,29}$ In summarizing their findings Lamb et al. ${ }^{29}$ concluded: "The reinforcing effects of morphine can occur in the absence of self-reported subjective effects and thus, do not appear to be causally related to drug-liking or euphoria" (p. 1172). These kinds of data are very important because they establish that the motivation to take drugs (drug wanting) is not always directly attributable to the subjective pleasurable effects of drugs (drug liking), and it is possible this is especially true in addicts. That is, one must consider the possibility that in addicts the subjective pleasurable effects and the motivational effects of drugs are merely correlated effects. They occur together most of the time, but they can be dissociated and there is no necessary causal relationship between them.

\section{Incentive-sensitization}

If compulsive drug-seeking and drug-taking behavior are often not motivated by either the desire to obtain pleasure or by the desire to relieve withdrawal, then what motivates addictive behavior in these instances? Why do addicts compulsively seek drugs? We have attempted to address these questions by proposing the concept of "incentive-sensitization".,30 The basic thesis of the incentive-sensitization view of addiction can be summarized in four points.

(1) Potentially addictive drugs share the ability to produce long-lasting adaptations in neural systems (i.e. addictive drugs change the brain).

(2) The brain systems that are changed include those normally involved in the process of incentive motivation and reward.

(3) The critical neuroadaptations for addiction render these brain reward systems hypersensitive ("sensitized") to drugs and drugassociated stimuli.

(4) The brain systems that are sensitized do not mediate the pleasurable or euphoric effects of drugs (drug "liking"), but instead they mediate a subcomponent of reward we have termed incentive salience or "wanting". ${ }^{3,19,30-33}$ It is the psychological process of incentive salience specifically that is responsible for instrumental drug-seeking and drug-taking behavior (drug "wanting").

We have hypothesized that when sensitized, this incentive salience process produces compulsive patterns of drug-seeking behavior. ${ }^{3,30}$ Through associative learning the enhanced incentive value becomes focused specifically on drug-related stimuli, leading to more and more compulsive patterns of drug-seeking and drugtaking behavior. Furthermore, the persistence of neural sensitization is hypothesized to leave addicts susceptible to relapse even long after the discontinuation of drug use. In the following we will review some of the evidence for incentivesensitization, and elaborate some of the major features of this view of addiction.

\section{Psychomotor sensitization}

Most studies showing that the repeated administration of drugs of abuse can produce sensitization (i.e. an increase in drug effect) involve measures of the psychomotor activating effects of drugs, such as their ability to enhance locomotor activity, rotational behavior or stereotyped motor patterns. ${ }^{3,34-36}$ The majority of these studies involve psychomotor stimulant drugs. Studies on the psychomotor activating effects of drugs are thought to be relevant to addiction because of the assumption that the neural substrate that mediates these effects is either the same as, or at least overlaps with, the neural substrate responsible for the rewarding effects of drugs. ${ }^{15}$ This neural substrate is, of course, the mesotelencephalic dopamine system, and especially dopamine projections to the nucleus accumbens and accumbens-related circuitry (often called the mesolimbic or mesocorticolimbic dopamine system).

There is now considerable evidence that the repeated intermittent administration of psychomotor stimulant drugs results in a progressive increase in their psychomotor activating effects, and an example of this effect is illustrated in Fig. 1. Although most studies of psychomotor sensitization involve the administration of psychomotor stimulants, such as amphetamine or cocaine, psychomotor sensitization has been reported with many other drugs of abuse as well, including methylphenidate, fencamfamine, morphine, 


\section{Psychomotor Sensitization}
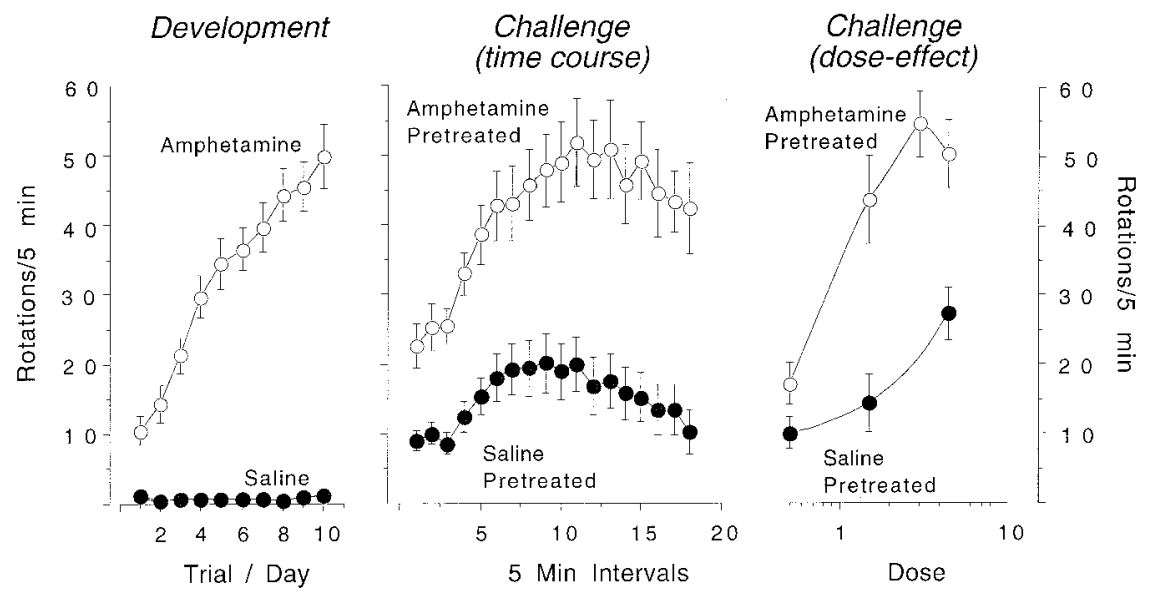

Figure 1. An illustration of three ways of quantifying sensitization of rotational behavior in rats with a unilateral 6-OHDA lesion given repeated i.p. injections of $3.0 \mathrm{mg} / \mathrm{kg}$ of d-amphetamine sulfate (data from Anagnostaras $\mathcal{E}^{\circ}$ Robinson $^{73}$ ). Left panel: mean ( $\pm S E M)$ number of rotations per 5-minute interval over 10 consecutive 90-minute test sessions in animals given amphetamine (open circles) or saline (closed circles). Test sessions were every 3-4 days. Sensitization is indicated by the progressive increase in drug effect seen with repeated amphetamine treatment. Middle panel: the time course of the behavioral response when both saline and amphetamine pretreated animals were given a challenge injection of $1.5 \mathrm{mg} / \mathrm{kg}$ of $d$-amphetamine. The challenge session was 3-4 days after the last (10th) pretreatment session. Sensitization is indicated by a significantly greater behavioral response in amphetamine than in saline pretreated animals. Right panel: sensitization can also be quantified by measuring the magnitude of the shift to the left in the amphetamine dose-effect function in drug versus saline pretreated animals (see Anagnostaras $\mathcal{E}$ Robinson $^{73}$ ).

phencyclidine, MDMA, nicotine and ethanol (for references, see Robinson \& Berridge ${ }^{3}$ ).

Most directly relevant to the topic of this volume on alcohol abuse is evidence for sensitization to ethanol. There is relatively little research on this topic, and it is especially difficult to study the psychomotor activating effects of drugs that also have motor depressant effects, such as morphine or ethanol. With morphine this problem has been obviated to some extent by using direct injections of the drug into the ventral tegmental area. Nevertheless, there is a growing literature that suggests the repeated administration of ethanol does indeed induce psychomotor sensitization. ${ }^{37-44}$ There is also evidence for cross-sensitization between ethanol and other drugs of abuse, including reports that pretreatment with ethanol enhances the subsequent psychomotor effects of cocaine, ${ }^{40}$ amphetamine $^{45}$ and morphine, ${ }^{46}$ and that cocaine pretreatment potentiates ethanol's effects. ${ }^{40}$ Cross-sensitization between stress and ethanol has also been reported. ${ }^{44}$ Especially relevant to the present discussion is evidence that repeated treatment with amphetamine increases ethanol intake when rats are tested 3 months after the cessation of amphetamine treatment, ${ }^{47}$ suggesting there may be long-lasting sensitization to ethanol's rewarding effects. ${ }^{48,49}$

Research on the neurobiology of ethanol sensitization is in its infancy, but there are reports that ethanol sensitization is associated with neuroadaptations in dopamine and accumbensrelated circuitry $^{40,46}$ that are reminiscent of changes seen with other drugs of abuse. For example, Nestby et $a l^{46}$ have reported that repeated treatment with cocaine, amphetamine, morphine or ethanol all increase the electrically evoked release of dopamine and acetylcholine from striatal slices in vitro. The extent to which different drugs of abuse induce similar neuroadaptations in brain reward circuitry remains an open question. It is highly likely, however, that different drugs will induce different adaptations, especially at the cellular and molecular level (e.g. White et $\left.a l .^{50}\right)$. It is possible that the overall outcome will be similar for the operation of neural systems that mediate the incentive moti- 
vational effects of drugs, including ethanol. This remains an important topic for future investigation.

Psychomotor sensitization is a very complex and rich phenomenon with many interesting features, most of which are not well understood. For example, for many drugs sensitization is typically seen only when drugs are administered intermittently, and the most robust sensitization occurs when injections are widely spaced in time. ${ }^{34}$ Sensitization is dose-dependent; the most robust sensitization occurs after treatment with relatively high doses. ${ }^{51,52}$ Sensitization is also often time-dependent. ${ }^{53}$ That is, sensitization is typically more evident long after the discontinuation of repeated drug treatment than shortly after the discontinuation of drug treatment. Perhaps the most remarkable feature of sensitization is its persistence. Once they have been sensitized, animals may remain hypersensitive to the psychomotor activating effects of drugs for months or years. ${ }^{34,54}$ There is relatively little parametric research on this aspect of sensitization, but its persistence is probably dependent on complex interactions among the dose administered, the interval between treatments, the number of treatments, the route of administration, the environment in which the drug is given, the sex and strain of the animal and, of course, what drug is administered. ${ }^{34,55-57}$ Finally, it important to emphasize that the ability of drugs to induce psychomotor sensitization is not a function of the fact that in most animal studies the drug is administered by the experimenter. There are now a number of reports that drug selfadministration experience also promotes psychomotor sensitization. ${ }^{58^{-60}}$

Individual differences in susceptibility to sensitization There are two other important features of sensitization that deserve mention. One is individual variation. There is enormous variation across individuals in susceptibility to sensitization. ${ }^{56}$ Even in animal studies, some individuals show rapid and robust sensitization with a given dose of a drug, whereas others sensitize very little, if at all. There are many factors that contribute to individual variation in the susceptibility to sensitization, including genetic, hormonal and experiential factors. For example, genetic factors have been implicated by studies showing that there are marked strain differences in the susceptibility to psychomotor sensitization in both rats ${ }^{61,62}$ and mice. ${ }^{44,56,63}$ Gonadal hormones have been implicated in studies reporting sex differences in susceptibility to sensitization, ${ }^{64-66}$ and these sex differences are attenuated by castration of male rats. ${ }^{66,67}$ Experiential factors have been implicated by studies reporting cross-sensitization between stress and psychostimulant drugs. ${ }^{44,56,68}$ The mechanisms by which these factors influence susceptibility to sensitization are largely unknown, although the factors that predispose animals to sensitization appear to be different than those that confer acute sensitivity to drugs. ${ }^{56,63,69-71}$ Nevertheless, the incentive ${ }^{-}$ sensitization theory posits that factors which render people susceptible to sensitization will also contribute to individual variation in susceptibility to addiction.

\section{Modulation of sensitization by the circumstances} surrounding drug administration

Another important feature of sensitization we want to emphasize is that sensitization is not an inevitable consequence of repeated exposure to drugs. Instead, the ability of drugs to induce or express sensitization is powerfully modulated by learning and the circumstances surrounding drug administration. ${ }^{72}$ There are at least two ways that the circumstances surrounding drug administration modulate sensitization. The first is modulation of the expression of neural sensitization that has already been induced. Perhaps the best example of environmental modulation of expression is the phenomenon of context-specific sensitization. In studies of this type, typically one group of animals receives drug injections in a unique test environment and another group receives injections in a different environment (often in its home cage). On the test day all animals receive a challenge injection in the same environment (the test environment). Only the animals treated with drug in the test environment usually express sensitization. The animals treated with drug in a different environment often fail to express sensitization in the test environment, where drug has never before been experienced. Thus, the expression of sensitization is said to be "context-specific". ${ }^{73-76}$ An implication for humans is that the expression of neural sensitization in addicts can be expected to be strongest in those contexts in which drugs have often been taken before. 
Despite this powerful associative (conditioned stimulus) control over the expression of sensitization there are at least two reasons to believe that neural sensitization occurs even in the animals that do not express behavioral sensitization. The first is that animals receiving drug treatments in an environment other than the test environment (e.g. in a "third world") develop normal behavioral sensitization in their drug treatment environment; they simply do not express it in a different environment that has never been paired with drug administration. ${ }^{73}$ Secondly, neural sensitization has been described under conditions that preclude the influence of contextual stimuli on the neurobiological expression of the drug response. For example, evidence for neural sensitization to a number of drugs has been reported using striatal tissue slices in vitro and in anaesthetized animals. ${ }^{46,77-81}$

It appears, therefore, that repeated exposure to amphetamine may induce neural sensitization non-associatively, but whether the consequences of neural sensitization are expressed at a particular place or time is determined to a large extent by conditional stimuli (especially contextual stimuli) that have been associatively paired with drug administration. ${ }^{73}$ Furthermore, it has been hypothesized that contextual stimuli may often act not only as traditional excitors (i.e. a $\mathrm{CS}^{+}$) to produce a conditioned response (CR), but as a different class of conditional stimuli known as occasion-setters, which can modulate drug responses without producing a CR. ${ }^{73}$ It may be that this interaction of neural sensitization with associative learning is responsible for the focus on drug-associated stimuli in addicts, whereby the acts and objects associated with drug-taking become especially powerful incentives themselves. Contextual modulation of the expression of sensitization may contribute to the critical role that context plays in precipitating relapse. That is, an implication for addiction is that the expression of sensitization to the incentive properties of drug-related stimuli may be strongest in contexts that have been also distinctly related to drug-taking in the past. The ability of context to act as an occasion-setter and to modulate sensitization would interact with the ability of specific drug-associated conditioned stimuli to trigger craving as a classically conditioned response, combining to provide very strong contextual control over both craving and relapse. ${ }^{3}$

The second way that the circumstances sur- rounding drug administration may modulate sensitization is to influence whether neural sensitization is induced in the first place (or at least the rate and extent of sensitization produced by a given dose of a drug). For example, there are now a number of reports that when low to moderate doses of amphetamine or cocaine are administered in the environment where an animal lives (i.e. at "home") they are less effective in inducing psychomotor sensitization than if the same doses are given in a relatively distinctive test environment; one that is novel to the animal until its first pairing with the drug. ${ }^{82-84}$ Indeed, if amphetamine is administered at home using a chronically indwelling i.v. catheter, so that drug administration is completely unsignaled, doses of $0.375-1.0 \mathrm{mg} / \mathrm{kg}$ (i.v.) fail to induce sensitization. ${ }^{72,85,86}$ The same doses do induce sensitization if drug administration is signaled by placement of an animal into a distinctly predictive test environment. A similar effect has also been seen with both cocaine ${ }^{51}$ and morphine (Badiani et al., unpublished studies). Further studies have established that the effect of unsignaled drug administration is not to completely preclude sensitization, but to shift the dose-effect curve for the induction of sensitization. When high enough doses of either cocaine or amphetamine are given sensitization is induced regardless of environmental condition. ${ }^{51,52}$

The ability of environmental context to modulate the induction of sensitization may be related to its ability to modulate the neural circuitry engaged by drugs. Badiani and colleagues ${ }^{87}$ recently reported, for example, that the ability of amphetamine to induce c-fos mRNA in the striatum is powerfully modulated by the environmental context in which amphetamine is administered. Indeed, it appears that that environmental context can modulate which cell populations in the striatum are engaged by amphetamine. When given at home amphetamine induced c-fos only in striatal neurons also positive for dopamine D1 receptor mRNA (not in cells positive for $\mathrm{D} 2$ receptor $\mathrm{mRNA}$ ); but when given in association with environmental novelty amphetamine induced c-fos in both D1 and D2 mRNA-positive neurons. ${ }^{88}$

In summary, sensitization is not an inevitable consequence of exposure to potentially addictive drugs. That is, it is not a simple pharmacological phenomenon, but both the expression and the induction of sensitization can be powerfully 
modulated by non-pharmacological factors, including environmental (and presumably psychological) factors associated with drug administration. The influence of environmental factors on sensitization has important implications not only for understanding the phenomenon, but for thinking about therapeutic approaches in treating addiction (see below).

\section{Sensitization and drug reward}

The studies reviewed above on sensitization to the psychomotor activating effects of drugs indicate that addictive drugs induce neural sensitization. However, by themselves they provide only indirect evidence that sensitization occurs to the incentive motivational or rewarding effects of drugs. ${ }^{15}$ More direct evidence that the neural substrate that is sensitized is involved in mediating drug reward comes from two other sources. The first are studies showing that not only do the psychomotor stimulant effects of drugs sensitize, but so do their rewarding effects. ${ }^{89}$ There are a number of reports that prior exposure to a variety of potentially addictive drugs enhances the later acquisition of both a drug selfadministration habit ${ }^{90-97}$ or a conditioned place preference. ${ }^{98-102}$ Prior sensitization to amphetamine also increases the "breakpoint" for amphetamine self-administration when rats are tested using a progressive ratio schedule, ${ }^{103,104}$ and the enhanced responding for a conditioned reward produced by intra-accumbens amphetamine is potentiated by cocaine sensitization. ${ }^{105}$ Furthermore, in recent studies Deroche et al. ${ }^{106}$ have found that experience with selfadministered cocaine later enhances the motivation to seek cocaine in, for example, a runway apparatus, and De Vries and colleagues in the Netherlands have reported that the ability of different drugs to reinstate (prime) drug-seeking behavior is positively related to whether they also show cross-psychomotor sensitization. ${ }^{107-110}$ Indeed, these latter researchers have reported, "all of the agonists that elicited sensitized locomotor responses in morphine- or amphetamine-pretreated rats ... appeared to cause reinstatement of previously extinguished heroin or cocaineseeking behavior, respectively. Taken together, these studies suggest a marked relationship between drug-seeking behavior and drug sensitization" (Vanderschuren et al., ${ }^{110}$, p. 251). Similarly, Deroche et al. ${ }^{106}$ concluded on the basis of their experiments that, "the progressive shift from cocaine use to dependence and the very high frequency of relapse of abstinent abusers probably originate from a sensitization phenomenon".

The ability of sensitization to enhance responsiveness to rewards does not appear to be confined to drug rewards, but also applies to other aspects of incentive motivation. Repeated treatment with either morphine $\mathrm{e}^{111}$ or amphetamine, ${ }^{112}$ for example, later facilitates the appetitive or anticipatory phase of a sexual encounter. Male rats sensitized to amphetamine later exhibit facilitated sexual behavior towards an estrus female, "as indicated by shorter latencies to mount and intromit, and a greater percentage of rats copulating" (Fiorino \& Phillips, ${ }^{112}$ p. 200). This sensitization-related facilitation of sexual motivation is accompanied by augmented dopamine efflux in the nucleus accumbens in response to presentation of a receptive female. ${ }^{113}$ In discussing their findings Fiorino \& Phillips ${ }^{12}$ (p. 206) raised the related and very interesting clinical observation that, "As many as $70 \%$ of patients admitted to a New York cocaine addiction treatment program were also reported to suffer from compulsive sexuality". ${ }^{14}$ Sensitization may also facilitate responding to learned properties of rewards (even though mesostriatal dopamine systems are not essential for reward learning ${ }^{19}$ ). This suggestion is consistent with recent reports that sensitization to amphetamine can facilitate the acquisition of both excitatory ${ }^{115,116}$ and inhibitory ${ }^{117}$ Pavlovian associations in a task using food (sucrose) reward. Harmer \& Phillips ${ }^{117,118}$ point out that the ability of amphetamine sensitization to facilitate behavior guided by Pavlovian learning may be related to its ability to enhance amphetaminestimulated dopamine efflux in both the nucleus accumbens ${ }^{115,119}$ and amygdala. ${ }^{115,116}$ The relative roles of the amygdala versus the accumbens in this associative facilitation are as yet unclear. $^{120}$

The second line of evidence that the neural substrate sensitized by drugs of abuse is involved in mediating drug reward comes from studies on the neurobiology of sensitization. There is not space here to review this large literature, but suffice it to say there is now considerable evidence that behavioral sensitization is associated with neuroadaptations in dopamine/accumbens systems. ${ }^{3,34,36,121-124}$ This is important because it 
is well established that these neural systems play an important role in mediating the rewarding effects of drugs and other incentives. ${ }^{15,125,126}$ Thus, if sensitization-related neuroadaptations are found in this mesocorticolimbic circuitry this is strong evidence that at least one neural system known to be critical for mediating drug reward undergoes "neural sensitization".

Both pre- and post-synaptic neuroplastic adaptations have been described in the dopamine/accumbens system of sensitized animals. An example of a presynaptic adaptation is a persistent increase in the ability of a variety of drugs to increase the overflow of dopamine in the nucleus accumbens and striatum of sensitized animals, in vitro and in vivo. ${ }^{3,34,46,79-81,121,122}$ Examples of postsynaptic adaptations include an increase in the sensitivity of dopamine D1 receptors $^{78,123}$ and a decrease in the sensitivity of glutamate receptors ${ }^{127}$ in the nucleus accumbens of sensitized animals (see Wolf ${ }^{124}$ for a review of the role of excitatory amino acids in sensitization). More recently it has been reported that both amphetamine and cocaine sensitization are also accompanied by persistent structural modifications in the morphology of output neurons in both the nucleus accumbens and prefrontal cortex. ${ }^{128,129}$ Repeated treatment with amphetamine or cocaine increases the length of dendrites on medium spiny neurons in the nucleus accumbens and on pyramidal neurons in the prefrontal cortex. This is accompanied by an increase in spine density on the distal dendrites of these cells. On medium spiny neurons there is an especially large increase in the number of branched spines; that is, spines with multiple heads. These structural data suggest that sensitization may involve more than a simple up- or downregulation of biochemical processes, but it may involve changes in patterns of synaptic connectivity in brain reward systems, changes that may be similar to those seen in other neural systems in association with other forms of experience-dependent plasticity. ${ }^{128,129}$ These observations are consistent with increasing evidence implicating neurotrophic factors in sensitization. ${ }^{130-132}$

To reiterate the basic thesis of the incentivesensitization view of addiction, it was originally proposed $^{3}$ that addictive drugs share the ability to produce persistent neuroadaptations in brain regions involved in the process of incentive motivation and reward, adaptations that render these regions hypersensitive ("sensitized"). It should be clear from the above that there is now a wealth of evidence to support this claim. The incentive-sensitization view also posits that it is largely because of sensitization of a neural substrate that mediates drug reward that with repeated drug use drugs gradually become more and more attractive (i.e. they acquire greater and greater incentive value), and become increasingly able to control behavior. Studies on sensitization of drug reward support this claim. Furthermore, we have suggested it is the persistence of neural sensitization that leaves addicts susceptible to relapse even long after the discontinuation of drug use. Studies on the relationship between sensitization and reinstatement in animal models support this claim as well. Of course, these latter hypotheses are more speculative, and are predicated on the assumption that repeated exposure to drugs of abuse can induce neural sensitization in humans. It is one thing to demonstrate incentive-sensitization in animals models, but-as critics of our theory occasionally point outquite another to demonstrate its occurrence in addicts.

\section{Sensitization in humans}

As might be expected from the difficulty in studying this issue in humans, there has been very little research on the topic of whether sensitization actually occurs in the brains of human addicts. It could be argued that the enormous increase in the incentive value of drugs in the development of addiction is de facto evidence for sensitization of a neural substrate that mediates this function in humans, but unfortunately for us, many will consider this argument insufficient. Until recently, the only direct evidence that repeated exposure to psychostimulant drugs can produce sensitization in humans came from studies on the phenomenology of amphetamine and cocaine psychosis. ${ }^{65,133-136}$ There is a considerable clinical literature that suggests repeated exposure to amphetamine or cocaine results in a progressive increase in their psychotomimetic effects, ${ }^{133}$ and that this enhanced sensitivity may persist long after the discontinuation of drug use. ${ }^{134,135,137}$ Related effects have been described in non-human primates. ${ }^{138}$

More direct evidence for sensitization to the psychomotor effects of amphetamine in humans has been lacking until only very recently, but 
there are now three reports of psychomotor sensitization in humans. Strakowski et al. ${ }^{139}$ first reported the results of a double-blind, placebocontrolled study in drug naive volunteers given two treatments ( 48 hours apart) with $0.25 \mathrm{mg} / \mathrm{kg}$ d-amphetamine. They found that the second treatment with amphetamine elicited a significantly greater increase than the first in four behavioral measures: activity/energy, mood, rate and amount of speech and eyeblink rate. In a second study Strakowski \& Sax ${ }^{140}$ replicated and extended these findings to see if three treatments with amphetamine would produce a progressive increase in drug effect, as is usually seen in animal experiments. Two measures increased progressively with repeated amphetamine treatment: activity/energy and eyeblink rate. Indeed, for eyeblink rate there was no effect of the first treatment with amphetamine, relative to placebo, but an increase in eyeblink rate emerged with subsequent drug treatments, even though the dose was the same. Interestingly, subjective ratings of drug liking did not increase with three drug treatments, which is consistent with our hypothesis that sensitization applies to "wanting" drugs but not to "liking" drugs (see below). These two studies involved within-subjects assessments of sensitization. More recently, Strakowski et $a l .^{141}$ reported evidence for significant psychomotor sensitization in humans using a between-subjects design. There has also been one report which failed to find evidence for cocaine sensitization in humans, ${ }^{142}$ but there are at least two reasons that this may be the case. First, as indicated by these authors in a letter to the editor of Biological Psychiatry, experienced cocaine users were used in this latter study and, therefore, "because of their extensive cocaine exposure prior to research participation [these subjects] may have already undergone the maximum sensitization process ... leaving no room for the relatively short-term, low-dose research exposure to demonstrate further sensitization" (Gorelick \& Rothman, ${ }^{143}$ p. 230). Secondly, as pointed out by Strakowski et al. ${ }^{144}$ in their response, "Rothman et al. concentrated on physiologic responses... [which] from animal studies ... would not be expected to exhibit sensitization ... and indeed, we also did not observe sensitization in vital signs measurements" (p. 230). Finally, additional evidence supporting the concept of incentive-sensitization in humans, relevant specifically to drug taking, comes from the interesting tentative observation of Bartlett et $a l .{ }^{145}$ that cocaine users who developed sensitization to the psychotomimetic effects of the drug have an elevated incidence of relapse, as indicated by more frequent rehospitalizations.

\section{Human imaging studies}

Neuroimaging studies of human addicts are also relevant to the incentive sensitization hypothesis of addiction. ${ }^{3}$ Especially germane, for example, is a study by Breiter and colleagues ${ }^{146}$ who used functional MRI to monitor signals related to blood flow in the brain of human cocaine addicts as they received intravenous cocaine or a vehicle. As expected on the basis of animal studies, they found that cocaine produced a rapid signal increase in many structures, including the nucleus accumbens, the neostriatum (caudate/putamen), many neocortical regions, ventral tegmentum and a variety of other brain areas. Signal decreases were seen in the amygdala, temporal pole and the medial frontal cortex. All these transient changes correlated with the cocaine rush or euphoric effects reported by the addicts. Most interestingly from the point of view of craving, however, were more sustained changes in cerebral blood flow that outlasted the euphoric rush, and that correlated best with subjective craving reports for more cocaine. Cravingcorrelated signal increases were found in the nucleus accumbens region, parahippocampal cortex and parts of the lateral prefrontal cortex. ${ }^{146}$ A craving-correlated decrease in signal was reported in the amygdala. Interestingly, one region to show bilateral activation during a saline retest was the nucleus accumbens, which the authors speculate could be related to expectancy for cocaine. Activation of this circuitry by stimuli that predict cocaine, as has been reported in animals studies (Berridge \& Robinson, ${ }^{19}$ for review), is certainly compatible with the incentivesensitization hypothesis.

A slightly different pattern of brain changes was found in a PET study by Childress et al. ${ }^{147}$ who showed former cocaine addicts and normal subjects videotapes with themes of drug-taking designed to pique an addict's craving for cocaine. Childress et al. ${ }^{147}$ did not distinguish anatomically between the nucleus accumbens and other parts of the neostriatum, but had only a single "caudate" category. The two brain regions that in addicts that showed the greatest 
change in cerebral blood-flow in response to viewing drug-related stimuli were the amygdala and the caudate. Blood flow increased significantly in the amygdala and decreased significantly in the caudate and lenticular nucleus. Non-addict normal subjects did not show any significant changes in blood flow in response to drug-related stimuli. In a related study Grant et al. ${ }^{148}$ found that increases in glucose metabolism were correlated with self-reports of craving provoked by drug-associated stimuli only in the prefrontal cortex, amygdala and cerebellum (see also Mass et $a l .{ }^{149}$ ), whereas Wang et al. ${ }^{150}$ reported changes in metabolism only in the orbitofrontal cortex, left insular cortex and cerebellum.

Recently, PET has also been used to quantify changes in blood flow in heroin addicts given either an injection of heroin, or exposed to heroin-related cues. ${ }^{151}$ In this study both heroin and heroin-related cues activated the same structures, especially a region of the midbrain centered on the periaqueductal grey (PAG) and ventral tegmental area (VTA). The PAG has projections to the VTA, and of course, the VTA is the origin of ascending dopamine projections to the nucleus accumbens and neocortex. Furthermore, these authors reported that: "midbrain activations predict responses to salient [drugrelated] cues in cortical and subcortical regions implicated in reward-related behavior", including the anterior cingulate, amygdala and dorsolateral prefrontal cortex (Sell et al., ${ }^{151}$ p. 1042).

It is difficult to draw strong conclusions, given the small number of studies so far, the limitations of imaging techniques, and the apparent discrepancies in results. It is interesting from the point of view of the incentive-sensitization hypothesis that in two studies of addicts the strongest craving-correlated signal changes were seen in the nucleus accumbens or caudate, as well as amygdala. ${ }^{146,147}$ These studies disagree in the direction of the accumbens/caudate signal change, one suggesting an increase in blood flow during craving and the other suggesting a decrease. The interpretation of this difference in direction is complicated by the different scales of anatomical and temporal resolution used in these studies, by reports that cocaine itself can produce cerebral vasoconstriction in humans, ${ }^{152}$ and by the possibility that the neural signal conveyed by dopamine may under some conditions be inhibitory (hyperpolarizing) and in other condi- tions excitatory. ${ }^{153,154}$ Nevertheless, there are now a reasonable number of imaging studies showing that the mesocorticolimbic projection systems are engaged when addicts are given drugs or when they are exposed to drugassociated stimuli, and that in some cases this is associated with reports of craving. Such data are entirely consistent with the incentivesensitization theory of addiction.

In summary, although there is little research in humans and it is fraught with technical limitations, the available evidence suggests that (a) repeated exposure to psychostimulant drugs can sensitize some drug effects in humans, and (b) the same mesocorticolimbic circuitry that in animals is known to mediate drug-seeking and to show neural sensitization is also powerfully engaged in humans upon exposure to drugs or drug-associated stimuli. Further studies on behavioral sensitization in humans will be critical in testing the notion of incentive-sensitization, but it is worth injecting a note of caution in interpreting negative behavioral studies. It is not obvious a priori which behavioral measures in humans will provide the most sensitive indicators of a sensitization process. This is even a difficult issue in animal studies. For example, it is often difficult to quantify behavioral sensitization using measures of locomotor activity, unless just the right dose and treatment conditions are used..$^{85}$ Also, in rats, some behaviors show robust sensitization, such as rotational behavior, repetitive sniffing and repetitive head movements, whereas other seemingly related stereotyped behaviors do not, such as oral movements. ${ }^{34,85}$ Furthermore, the doses used in studies with humans are lower than those typically used in animal studies, and drugs are often given orally. These conditions may produce only marginal sensitization even in animals. ${ }^{51,52}$

Finally, one needs to keep in mind that for the most part indices of behavioral sensitization are important only as secondary measures because they provide indicators of underlying neuroadaptive processes (neural sensitization), and it is neural sensitization that is critical or primary for incentive-sensitization predictions regarding addiction. Even in animal studies, the fact that a behavior like rotational behavior sensitizes is of interest only because the change in behavior provides an indicator of an underlying neuroadaptive process, and because we know a great deal about the neural systems that mediate this be- 
havior, and thus have some clues as to what neural systems might be effected. The incentivesensitization hypothesis makes strong predictions regarding neural sensitization in human addicts, but not necessarily about what which specific behaviors might best reflect neural sensitization (even though inferences can be drawn from animal studies). The critical prediction made by the incentive-sensitization view of addiction is this: the brains of human addicts who compulsively crave drugs will contain a neural substrate that has been rendered sensitized by drugs. A role of that neural substrate will be to mediate the incentive salience of drug rewards. Further, individuals will differ in their susceptibility for sensitization of that neural substrate, and those who sensitize most readily will be most at risk for addiction. These predictions are testable, and so the incentive sensitization theory of addiction can be confirmed or disproved on the basis of empirical evidence.

A better understanding of the nature of neural sensitization, based on animal studies, will be crucial to developing proper tests of the theory in human addicts. Once we understand the neural basis of sensitization in non-human animals we should be able to determine if the same neuroadaptions exist in the brains of addicts. If they do not, the incentive-sensitization theory is proved wrong. Of course, this proof first requires that we understand which neurobiological adaptations produced by repeated treatment with drugs are causally related to the development of sensitization, which we do not, as yet. Secondly, it will require that adequate technological tools be developed to quantify the relevant neuroadaptations, in the relevant brain regions in humans, which given the rapid advances in this field, should appear in the future. Thus, future research on neuroadaptations engendered by drug use in humans, derived from an understanding of the development of neural sensitization in animal models, will eventually provide a final test of the notion of incentive-sensitization.

\section{"Wanting" versus "liking"}

The final crucial issue we would like to address concerns the nature of the psychological process that is mediated by the neural substrate that undergoes sensitization. To the extent this is the dopamine/accumbens system it concerns the nature of the incentive and reward function medi- ated by this system. This leads us to the topic of what we have termed "wanting" versus "liking". 3,19,30,32,33,155

It is often assumed that the primary role of the dopamine/accumbens systems in reward is to mediate the subjective pleasurable or hedonic aspects of reward ("liking"). This view was stated most explicitly in Wise's ${ }^{156}$ anhedonia hypothesis of dopamine function (also Gardner \& Lowinson ${ }^{157}$ ). Wise ${ }^{156}$ argued that after disruption of dopamine neurotransmission by treatment with dopamine antagonists, "all of life's pleasures-the pleasures of primary reinforcement and the pleasures of their associated stimuli-lose their ability to arouse the animal" (p. 52). Although this view is no longer held by Wise, ${ }^{158}$ dopamine is typically associated with pleasure in popular media accounts, ${ }^{159,160}$ and this view is implicit or explicit in many scientific discussions of dopamine and reward. ${ }^{19}$ For example, it is often argued that a suppression in dopamine neurotransmission mediates anhedonia during drug withdrawal, ${ }^{5,161-164}$ a view that is a direct extension of Wise's anhedonia hypothesis of neuroleptic action.

The idea that drug pleasure is mediated by dopamine systems continues to be endorsed by a number of neuroscientists who study addiction. In their own words, for example, Gardner \& Lowinson $^{157}$ (p. 360) stated, "a subportion of the mesolimbic dopamine neurons originating in the ventral tegmental area ... and synapsing into the nucleus accumbens and adjacent areas ... appears highly specialized for carrying neural messages encoding hedonic tone" [our italics]. Thus, suppression of the dopamine system is often held, as by Wise originally, to produce dysphoria or anhedonia. In an explicit statement of this hypothesis Dackis \& Gold ${ }^{5}$ graphically illustrated in their Fig. 4 the opinion that: "Since increased dopamine neurotransmission can produce euphoric states, dopamine depletion after cocaine use may lead to cocaine urges and dysphoria" (p. 473). This view was more recently reiterated by Markou, Kosten \& Koob, ${ }^{165}$ who posit that "Based on the ample evidence for a role of mesocorticolimbic dopamine neurotransmission in reward and incentive/motivational processes, and that abnormalities in these two processes (i.e., inability to experience pleasure and loss of motivation) constitute core symptoms of depression, a dysfunction in the mesocorticolimbic dopaminergic system may be mediating these 
symptoms" (p. 150; italics added). Similarly, Di Chiara \& $\operatorname{Tanda}^{166}$ (p. 353) posit that the capacity for pleasure is so closely linked to dopamine that a physiological measure of dopamine neurotransmission should be able to index psychological pleasure, proposing that "as a biochemical test for anhedonia... [one may measure] the blunting of DA neurotransmission in the Nac 'shell'". Most investigators do not make that inferential leap, but many appear to presume that measures of neural activity in the mesolimbic dopamine projection system reflect the hedonic impact of an event. For example, Childress and colleagues ${ }^{147}$ (pp. 11-12) hypothesize that "brain structures activated during cocaine craving may be among those activated by cocaine itself, including the dopamineinnervated limbic regions implicated in cocaine's pleasurable effects" (italics added). Indeed, on the basis of PET studies with cocaine Volkow et al. ${ }^{167}$ reported, "The magnitude of the selfreported high was correlated with the degree of dopamine transporter occupancy" (p. 827).

If a depression in dopamine neurotransmission leads to anhedonia, it follows according to the hedonia hypothesis that enhanced dopamine neurotransmission should lead to enhanced pleasure. If that were true, then sensitized human addicts should gain more pleasure than usual from their drugs. Indeed, Koob \& Le $\mathrm{Moal}^{10}$ (p. 52), in a discussion of drug abuse and hedonic dysregulation, note first that, "the facilitation of dopamine neurotransmission in the mesocorticolimbic dopamine system appears to be critical for the acute reinforcing actions" of drugs of abuse, and go on to equate the positive reinforcing effects of drugs with hedonic euphoria. They then explicitly incorporate sensitization into their explanation of addiction by graphically describing sensitization as producing a $10-20 \%$ increase in a drug's positive effect along a hedonic scale (see their Fig. 4B, p. 56). In other words, they postulate that repeated drug use may sensitize or increase an addict's experience of the hedonic effect of a drug: enhanced drug "liking" as well as drug "wanting" (in contrast to our view that sensitization applies to drug "wanting" but not to drug "liking"; see Fig. 2 below).

On the other hand, in different accounts Koob and colleagues have hypothesized instead that addiction is not driven primarily by an increase in the hedonic impact of drugs themselves, but rather driven by the negative hedonic conse-
Sensitization of "wanting" but not "liking" (Robinson \& Berridge model)

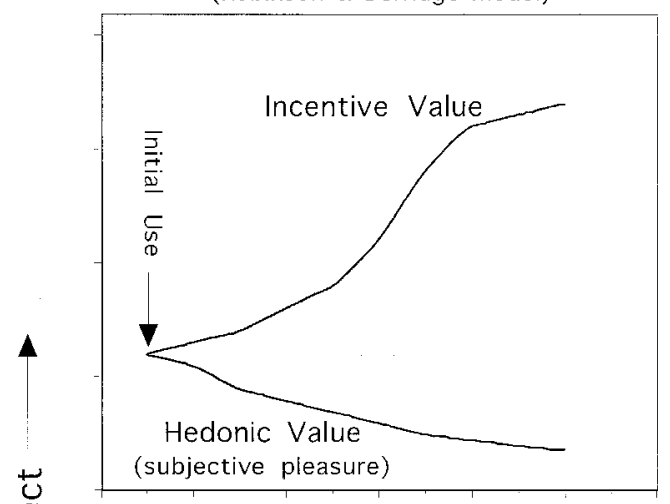

Sensitization of "wanting" and "liking" (Koob \& Le Moal model)

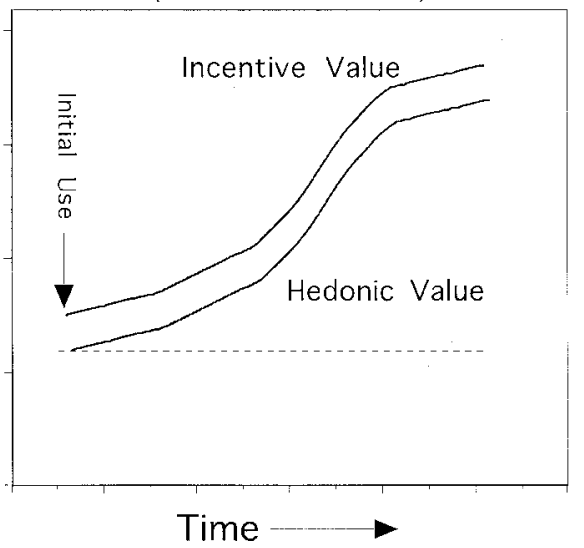

Figure 2. A schematic illustration of the hypothetical relationship between changes in the incentive value of drugs (drug "wanting") and changes in the ability of drugs to produce subjective pleasurable effects (drug "liking") during the development of addiction. The top panel indicates the relationship posited by the Robinson $\mathcal{E}$ Berridge ${ }^{3}$ incentivesensitization view. Robinson $\mathcal{E}$ Berridge ${ }^{3}$ argued that in the development of addiction sensitization leads to enhanced "wanting" due to sensitization of the neural substrate responsible for incentive salience, while at the same time there is either no change or a small decrease in the hedonic effects of drugs (see Robinson $\mathcal{E}$ Berridge for a full discussion). The bottom panel indicates the relationship posited by Koob \& Le Moal ${ }^{10}$ in their Fig. 4B. They indicate that sensitization is characterized by an increase in the intensity of the primary drug effect along a hedonic scale. That is, in the development of addiction they suggest there is not only an increase in the incentive value of drugs ("wanting" in our terms) but also an increase in hedonic effect ("liking" in our terms).

quences of discontinuing drug use..$^{8-10,165}$ They argue, for example, that suppression of dopamine neurotransmission in withdrawal pro- 
duces "hedonic homeostatic dysregulation" or dysphoria, and suggest addicts seek drugs to re-establish "hedonic homeostasis" by taking more drugs to restore dopamine neurotransmission to normal levels. ${ }^{10}$ In yet another account Koob and colleagues ${ }^{168}$ have posited that addiction is characterized by an increase in a "hedonic set point", whereby drug intake is escalated, they say, because individuals, "are trying to reach and then to maintain a higher state of intoxication" (p. 300). Thus, in this latter formulation, there is no sensitization to the hedonic impact of the drug itself, but only, "a change in the hedonic set point" (p. 299). It is unclear whether a set point for pleasure actually exists, as the set point concept implies that organisms should choose to increase pleasure only to the level of their set point, and not beyond that level. The only evidence for a hedonic set point seems to be that individuals achieve stable levels of drug selfadministration. Stable self-administration might be explained by several factors, so one hopes that a clearer explanation will be forthcoming by the authors of what such a set point entails.

Despite their inconsistencies, all these hypotheses share in common the idea that hedonic state is what regulates compulsive patterns of drugseeking and drug-taking behavior in the addict, and that changes in dopamine neurotransmission move an individual up and down along an hedonic scale. Many authors do not link dopamine neurotransmission with drug pleasure so explicitly, as do Koob and colleagues, but many do posit essentially the same point implicitly, by substituting terms such as "reinforcement" for the function mediated by dopamine neurotransmission in ways that are difficult to distinguish from hedonic impact (e.g. Volkow et al. ${ }^{167}$; see footnote 3 in Berridge \& Robinson ${ }^{19}$ for a discussion of this point). Thus, it seems clear that the dopamine hedonia hypothesis is not only found in popular media accounts of dopamine's function in reward, but it still lives in the scientific literature. Although it is possible in principle that dopamine systems mediate hedonic processes, and that drug pleasure might show sensitization, as Koob \& Le $\mathrm{Moal}^{10}$ have proposed, we must emphasize that this view differs in at least two ways from our concept of incentive-sensitization. First, the incentivesensitization theory holds that drugs can activate positive core processes of motivation in the absence of conscious awareness, so that positive effects may not be indicated on any scale of subjective affective intensity. ${ }^{3,19,30,155}$ For example, as discussed above, drugs that activate dopamine systems may promote drug-taking behavior in the absence of any subjective hedonic effects, ${ }^{22,24,29}$ which is not consistent with the notion that the positive reinforcing effects of drugs can be equated with their hedonic impact. Secondly, the incentive-sensitization theory explicitly posits that hedonic affect, either as subjective pleasure or its underlying core process ("liking"), is not the component of drug reward that is sensitized in addiction, and is not the psychological process that is mediated by dopamine systems. ${ }^{3,19,33}$ Instead, we have hypothesized that dopamine systems are crucial to the "wanting" component of incentive motivation. ${ }^{3,19,33}$ Indeed, there is convincing evidence to support the view that mesoaccumbens dopamine systems do not mediate hedonic processes, but rather mediate a separable "wanting" component, namely incentive salience, in motivation and reward. 3,19,31-33,169

The evidence that dopamine systems to not mediate hedonic processes has been reviewed recently by us, ${ }^{19}$ and so the main points are summarized only briefly here. First, there is now evidence from studies using neurochemical lesions, dopamine agonists or antagonists and other manipulations which shows that alterations in dopamine neurotransmission have no effect on the ability of rats to make judgements about the hedonic properties of taste stimuli ${ }^{19}$ (for reviews, see Berridge ${ }^{33}$ ). For example, experiments with rats that have complete striatal dopamine depletions have established that caudate and accumbens dopamine is not necessary for rewarding taste stimuli to elicit normal hedonic reactions. ${ }^{19,31,33,170}$ Secondly, there is an large literature showing that dopamine and accumbens neurons often discharge in anticipation of rewards, not during actual commerce with an expected reward, when the most pleasure is presumably experienced. ${ }^{171,172}$ Thirdly, it is well established that dopamine systems are activated not only by positive stimuli, but by aversive, painful and stressful stimuli and events (for references, see Berridge \& Robinson ${ }^{19}$ and Salamone et $a l .{ }^{173}$ ). Fourthly, there is a growing literature indicating that even in humans dopamine antagonists, such as pimozide or haloperidol, fail to reduce amphetamine-induced ratings of pleasure or euphoria - even when the 
same antagonists reduce ratings of how much amphetamine is wanted; i.e. a subjective liking/ wanting dissociation (for review, see Berridge \& Robinson, ${ }^{19}$ Berger et al., ${ }^{174}$ Brauer \& DeWit, ${ }^{175,176}$ and Ohuoha et al. ${ }^{177}$ ). Fifthly, enhancing dopamine neurotransmission is not sufficient to produce pleasurable subjective effects in humans (for review, see Rothman \& Glowa ${ }^{178}$ ). For example, Volkow et al. ${ }^{179}$ (p. 14) state: "blockade of striatal dopamine transporters by intravenous methylphenidate [in humans] is not sufficient to induce self-reports of 'high'”. Thus, points 4 and 5 together suggest that in humans increased dopamine neurotransmission is neither necessary nor sufficient for psychostimulants to produce subjective pleasurable effects.

In summary, despite correlational evidence for a relationship between dopamine activation and subjective pleasure in some instances (for example, Volkow et al. ${ }^{167}$ ), a more thorough examination of the evidence does not support the hypothesis that this represents a necessary causal relationship, or that dopamine mediates pleasure. ${ }^{19,173}$ Given that the role of the dopamine/ accumbens system in reward is not related to the hedonic aspects of reward, what is its contribution? What is the nature of the psychological process that is "sensitized" in the addict?

We have interpreted the role of the dopamine/ accumbens system in reward, and the role of sensitization of this substrate in addiction, in the context of a view of incentive motivation developed from studies on the neural systems responsible for taste hedonics. This view is an extension of traditional psychological models of incentive motivation developed by theorists such as Bindra $^{180}$ and Toates. ${ }^{181}$ In these traditional models of incentive motivation, which coincide with the common view expressed in much of the literature, it was hypothesized that a single process mediates both incentive value (how much an incentive is "wanted"), and hedonic value (how much it is "liked"). Incentives were hypothesized to have incentive value because of their ability to produce pleasure- "wanting" and "liking" were therefore necessarily connected and treated as explanations for positive reinforcement (in a non-circular sense). In our extension of these earlier models, however, we have hypothesized that the psychological process and neural substrate responsible for motivating behavior, for determining incentive value ("wanting"), is separable from the psychological process and neural substrate that mediates hedonics ("liking"; $3,19,32,33$ ). Manipulations of mesotelencephalic dopamine systems alter "wanting" more directly and powerfully than they alter "liking". ${ }^{19}$

It is further hypothesized that the psychological process that leads to "wanting" involves the attribution of attractive salience to stimuli and their representations, a process we call incentive salience attribution. We have suggested it is the process of incentive salience attribution that transforms the sensory features of ordinary stimuli or, more accurately, the neural and psychological representations of stimuli, so that they become especially salient stimuli, stimuli that "grab the attention", that become especially attractive and wanted, thus eliciting approach and guiding behavior to the goal. ${ }^{3,19,33}$ It is incentive salience that determines the value of incentives, and that controls seeking and instrumental behavior regarding them. ${ }^{19}$

The major feature of our view of incentive motivation that distinguishes it from earlier models is that it posits there are at least two distinct psychological processes involved in reward: (a) subjective pleasure ("liking"), and (b) incentive salience attribution ("wanting"). These two psychological processes are mediated by different neural systems. Furthermore, it is suggested that the neural systems that are sensitized by addictive drugs are those involved specifically in incentive salience attribution. ${ }^{3}$ The neural systems that mediate the subjective pleasurable (hedonic) effects of drugs do not appear to sensitize. This may be why addiction is characterized by an increasing dissociation between the incentive value of drugs (how much they are wanted) and their subjective pleasurable effects (how much they are liked). With the development of an addiction drugs become pathologically wanted ("craved") and this can occur even if drugs are liked less and less. The distinction between the Robinson \& Berridge ${ }^{3}$ "incentive salience sensitization" view and the Koob \& Le $\mathrm{Moal}^{10}$ "hedonic sensitization" view is illustrated graphically in Fig. 2.

Finally, it is interesting to consider that the neural system responsible for incentive salience attribution can sometimes produce goal-directed behavior ("wanting") not only in the absence of subjective pleasure, as discussed above, ${ }^{29}$ but in the absence of conscious awareness of "wanting" itself. $^{30,33,155}$ Activation of this system may con- 
stitute an implicit rather than explicit psychological process, similar to implicit memory or to implicit perceptual processes, ${ }^{182,183}$ and can act sometimes as an unconscious motivational process. $^{3,30,155}$ We become aware of its activation only by engaging interpretive cognitive processes needed to translate implicit activation into explicit subjective feelings. ${ }^{19,184-186}$ It may be because these psychological processes often operate outside of conscious awareness that addicts have so little insight into why they want drugs so much. Addicts may report they are miserable, their life is in ruins, and that even the drug is not that great anymore. They are themselves bewildered by the intensity of their own compulsive behavior. Indeed, addicts probably have no more insight into what motivates their daily behavior than do the rest of us; which is arguably, not much $^{186-188}$ (for additional discussion and references, see Berridge \& Robinson ${ }^{30}$ and Berridge $^{155}$ ).

The incentive--sensitization view of addiction has focused on drug-induced alterations in accumbens-related circuitry and associated changes in motivational processes, and how these may enhance associative learning. We must emphasize, however, that incentive-sensitization is just one contributor to addiction, and that drugs of abuse produce persistent alterations in many neural systems, altering many other psychological processes. Some of these may contribute directly to the development and/or manifestation of sensitized incentive salience, and others may contribute to addiction via alternate mechanisms. For example, in addition to drug hedonic processes, withdrawal-related processes and incentive salience processes, Phillips and his colleagues ${ }^{115-118}$ have described sensitization-related changes in dopaminergic activity in the amygdala that may directly facilitate Pavlovian learning. Sarter \& Bruno ${ }^{189}$ recently reviewed evidence that sensitization also increases the activity of basal forebrain cholinergic neurons, leading to enhanced cortical acetylcholinemediated activity. They hypothesized that this may lead to alterations in attentional processes, in particular, cognitive or hyperattentional states that may contribute to the pathological levels of incentive salience attributed to drug-related stimuli. Finally, a number of researchers have suggested that repeated exposure to psychostimulant drugs may result in frontocortical dysfunction and associated cognitive deficits, including impairments in decision-making and judgement. ${ }^{190}$ Indeed, there is increasing evidence that cocaine addicts show both neuropsychological $^{191,192}$ and neurobiological ${ }^{191,193-195}$ signs of frontal dysfunction. Resulting impairments of cognitive strategies to avoid drug use ${ }^{196}$ or to control impulsivity ${ }^{190}$ might interact with the increased motivation to seek and take drugs via the process of incentive-sensitization described here. Thus, in the addict, drugs may become increasingly "wanted" while at the same time the ability to make reasoned judgements about the future consequences of continued drug use becomes increasingly impaired. How these druginduced alterations in motivational, attentional and cognitive processes interact to produce the compulsive patterns of drug-seeking and drugtaking behavior that characterizes addiction remains an important challenge for future research.

\section{Implications for therapy}

In closing, we would like to point out that the incentive-sensitization view of addiction has a number of implications for therapy. First, it suggests that pharmacotherapeutic approaches which fail to address the neuroadaptive processes that lead to addiction in the first place will probably provide only symptomatic relief, and in the long term will probably be of limited efficacy. For example, the treatment of withdrawal symptoms by themselves has proven to have little effect in the long-term. ${ }^{18}$ We suggest that this is because avoidance of withdrawal is not the fundamental motivating force in addiction. Thus, the incentive-sensitization view of addiction predicts that the most efficacious medications will either (a) reverse the neuroadaptations that underlie incentive-sensitization and/or (b) prevent the expression of neural sensitization in behavior; i.e. inhibit the output of a sensitized "wanting" system.

There are, of course, many potential limitations of drugs with such effects. For example, it is not clear whether it is possible to develop an agent that could reverse specifically drug-experience dependent plasticity, without effecting other forms of experience-dependent plasticity that are probably very similar at the cell and molecular level. Also, most human addicts are polysubstance abusers, and it is not obvious whether any single agent would be effective if 
different drugs of abuse induce different sensitization-related neuroadaptations. Furthermore, these pharmacotherapeutic approaches are not likely to have long-term efficacy in the absence of psychotherapeutic and social supports that alter life style. For example, a medication that reversed sensitization-related neuroadaptations would not be effective if after treatment a person resumed drug-taking, and reinitiated the sensitization process. Nevertheless, the classes of medications currently in use probably do not directly attack the problem of reversing incentive--sensitization.

\section{Substitution approaches}

Opiate addicts can be maintained for long periods of time by substitution of heroin or morphine with long-acting mu opiate receptor agonists, such as methadone or levo-alpha acetyl methadyl (LAAM), and more recently by partial agonists such as buprenorphine. This approach has prompted interest in developing analogous long-lasting substitutes for cocaine. Although substitution therapies might be effective in managing addictive disorders, it must be acknowledged that they do not eliminate the addiction. They simply substitute one addictive drug for another that has more benign pharmacological properties. These substitutes are themselves chronically self-administered and may promote the same neuroadaptive processes as the originally abused agent, thus maintaining the strength of an addiction. There is certainly no evidence that they can reverse neuroadaptive processes, such as neural sensitization, that may have produced addictive behavior in the first place.

\section{Antagonists}

Antagonist therapies, such as naltrexone, have different implications regarding the incentivesensitization theory. Antagonists that block opioid receptors may suppress a component of reinforcement involving "liking" as well as "wanting". 3,33 Presumably, they might be effective in preventing the development of an addiction, and may possibly also prevent the re-boosting of incentive salience attributions that would otherwise strengthen the addiction further (for discussion of re-boosting and incentive salience, see Berridge \& Robinson ${ }^{19}$ ). However, there is no reason to believe that opioid antagonists are capable of permanently reversing any of the neuroadaptations in an addict that lead to incentive sensitization, and so an individual may still remain at risk to relapse.

\section{Antidepressants}

A variety of antidepressants have been used over the years in the treatment of addiction, based in part on the assumption they will reduce symptoms of depression (e.g. anhedonia) in withdrawal, and that by itself should be useful in treating addiction. For example, there were initially enthusiastic reports on using tricyclic antidepressants, such as desipramine, in treating cocaine dependence. ${ }^{197}$ However, later studies suggested that the initial enthusiasm was not warranted. ${ }^{197-199}$ Indeed, there have been reports that tricyclics may in some instances actually promote relapse. ${ }^{200}$ This may be because such agents promote catecholamine neurotransmission, and this can "prime" drug responding (promoting drug "wanting" from our point of view). Indeed, repeated treatment with desipramine has been reported to induce sensitization of dopamine neurotransmission. ${ }^{201}$ Obviously, from an incentive-sensitization view, this would be disadvantageous.

More recently, a different antidepressant, bupropion (Wellbutrin), has been reported to increase abstinence from cigarettes for smokers. $^{202,203}$ Bupropion is a monoamine uptake blocker, and modulates both norepinephrine and dopamine activity. ${ }^{204-206}$ However, bupropion also increases the level of mRNA expression for the dopamine transporter within the ventral tegmental area and substantia nigra. ${ }^{205}$ Increased numbers of the transporter molecules after this drug could facilitate re-uptake, and so exert a suppressive effect on dopamine neurotransmission that would oppose the original re-uptake blocking action ${ }^{207,208}$ (Dr K.Y. Little, personal communication). If bupropion acts on craving specifically, rather than on general aspects of depression that contribute to smoking behavior, then suppression of dopamine neurotransmission would be expected to be more useful than facilitation from our point of view.

Since smokers take the drug chronically, and craving is affected over months, the long-term effects of taking the drug are likely to be most important to its therapeutic action. As with most 
antidepressants, the long-term effects of this drug are least understood. However, as with desipramine, there is evidence that repeated treatment with bupropion can itself induce behavioral sensitization, and "bupropion-induced behavioral sensitization is accompanied by a selective potentiation of the effects of this compound on interstitial dopamine concentrations in the nucleus accumbens" ${ }^{209}$ (p. 7). If neural sensitization occurs after therapeutic doses of bupropion, then the incentive-sensitization theory must certainly regard it as a less than ideal drug for treating addiction.

\section{Acamprosate}

Acamprosate has been described as a "partial co-agonist" for NMDA glutamate receptors, although its effects on NMDA transmission appear to be complex and possibly statedependent. ${ }^{210,211}$ Called an "anti-craving" drug, it has been reported to increase the proportion of alcoholics who successfully abstain from alcohol for several months (although possibly not beyond ${ }^{212}$ ) and reduces some of the acute psychological and physiological consequences of alcohol and morphine withdrawal. ${ }^{213,214}$ It is possible that acamprosate might act in part by modulating the sensitized incentive salience of drugrelated stimuli. If acamprosate acts primarily on NMDA receptors, if the location of those NMDA receptors were in the mesoaccumbens system or its major connections, and if NMDA receptors are important mediators of the expression of neural sensitization, ${ }^{124}$ (124) then it might conceivably interfere with an NMDA mechanism involved in the expression of sensitization. Clearly, however, this hinges on a number of assumptions, and so the relation between acamprosate and the incentive-salience hypothesis must remain unclear for the time being.

\section{Immunotherapies}

Finally, there recently has been interest in developing immunotherapies for cocaine abuse, ${ }^{18}$ which involve treatment with primary antibodies or catalytic antibodies to cocaine. These treatments effectively reduce the amount of cocaine that reaches the brain. Of course, this approach also fails to reverse the neuroadaptive processes responsible for addiction, even though it may impede their further growth. Because of this failure to address persisting neural sensitization, cocaine addicts treated with such vaccines may still crave the drug. They might satisfy their desire by either taking enough cocaine to overcome the antibody, or by taking a different psychostimulant, such as amphetamine, which is not targeted by the vaccine. Indeed, one might fear that such vaccines could exacerbate some of the social problems associated with cocaine abuse, such as spurring some individuals to commit more crimes, because recidivist addicts would require more money to obtain the additional cocaine needed to overcome the antibody.

\section{Future pharmacotherapies}

The ability of existing drugs to treat addiction (other than perhaps substitution therapy) is far from impressive. Success for anti-craving drugs is typically measured as a modest increase in the percentage of addicts who give up their drugs for a few months, or even just a few weeks. For several therapeutic drugs, such as some antidepressants, even this goal is often not reached. Clearly, current drugs provide no magic bullet drug therapy for addiction. So what are the prospects for better drugs in the future?

The incentive sensitization theory does not rule out the possibility of more effective drug therapies, but it highlights that a pharmacological "cure" for addiction is a difficult task. Using drugs to block the development of sensitization should be effective, and in animals studies many such dopaminergic and glutaminergic agents have been identified. ${ }^{124}$ However, it is unlikely that people would be willing to take such agents before they become addicts, and so these are not likely to be useful therapeutic tools. The optimal approach presumably would be to reverse the neural changes underlying sensitization in addicts. Given that sensitization appears to involve complex changes in patterns of synaptic connectivity in regions such as the nucleus accumbens and prefrontal cortex and multiple biochemical adaptations in monoamine and excitatory amino acid neurotransmitter systems, ${ }^{122-124,128,129}$ it seems unlikely that a pharmacological agent could reverse all these neuroadaptations-and possibly more-without disrupting other neural processes necessary for normal brain function.

Also, as mentioned above, it is not clear whether a single agent could target the multiple neuroadaptations likely to be associated with the poly- 
substance abuse typical of addicts. However, these are empirical questions that will only be answered by future research.

It might be more reasonable to hope to modulate the expression of neural sensitization, even if one could not reverse it. A drug therapy that acted to block the attribution of sensitized incentive salience to drug-related stimuli and associated representations might well reduce addictive craving and compulsive drug taking. Therapeutic drugs that target the neural mechanisms involved in the expression of sensitized incentive salience may offer the best hope of pharmacotherapies for addiction from the point of view of the incentive-sensitization theory. ${ }^{124,125}$ It is even possible that some current drugs, to the degree that they target craving at all, might interact with neural mechanisms that express sensitization. Future therapeutic drugs might be developed to do this better, especially when the mechanisms that express sensitized incentive salience are more fully understood.

However, in developing such compounds the incentive-sensitization theory posits that their neural target must be the neural substrate responsible specifically for sensitized incentive salience, and it is not well established that this substrate is the same as that responsible for psychomotor sensitization. ${ }^{216,217}$ There may be multiple neural systems sensitized by repeated exposure to drugs of abuse that mediate different behaviors, but according to incentivesensitzation theory only the neural substrate responsible for incentive salience ("wanting") is crucial in addiction. In developing preclinical models it will be important to determine the relationship between the sensitization of different behaviors (e.g. locomotion, different stereotypies, self-administration, post-stereotypy hyperactivity, rotational behavior, etc.), and the sensitization of different neural substrates. It will also be important to identify which of these substrates is most predictive of the sensitization of incentive salience relevant to addiction.

\section{Psychotherapies}

To end on a positive note, the incentive-sensitization theory suggests that in the absence of effective pharmacotherapeutics and, despite the persistence of neural sensitization, properly applied psychotherapeutic (including behavioral) approaches may be effective in treating addic- tion. They may offer the best hope for addicts today. This is because environmental (and presumably psychological) factors can powerfully modulate the expression and development of sensitization, as discussed above. ${ }^{72,73}$ This suggests that behavioral/cognitive mechanisms may be employed to gate the output of the sensitized neural systems mediating core motivational processes, thus preventing their expression in behavior. Sadly, the persistence of neural sensitization may mean, to paraphrase Alcoholics Anonymous, that in a neurobiological sense once an addict always an addict. But by developing effective long-term behavioral, cognitive and psychosocial support structures one should be able to manage more effectively the urges arising from drug sensitized neural systems that mediate the basic motivational processes discussed here.

\section{References}

1. Institute of Medicine Committee on Opportunities IN DRUg Abuse Research (1996) Pathways of Addiction (Washington, DC, National Academy Press).

2. Edwards, G. (1981) Nomenclature and classification of drug- and alcohol-related problems: a WHO memorandum, Bulletin of the World Health Organization, 59, 225-242.

3. Robinson, T. E. \& Berridge, K. C. (1993) The neural basis of drug craving: an incentivesensitization theory of addiction, Brain Research Reviews, 18, 247-291.

4. Markou, A., Weiss, F., Gold, L. H. Caine, S. B., Schulteis, G. \& Коов, G. K. (1993) Animal models of drug craving, Psychopharmacology, 112, 163-182.

5. Dackis, C. A. \& Gold, M. S. (1985) New concepts in cocaine addiction: the dopamine depletion hypothesis, Neuroscience Biobehavioral Reviews, 9, 469-477.

6. JafFe, J. H. (1990) Drug addiction and drug abuse, in: Gilman, A. G., Rall, T. W., Nies, A. S. \& TAYlor, P. (Eds) The Pharmacological Basis of Therapeutics, pp. 522-573 (New York, Pergamon Press).

7. WikleR, A. (1948) Recent progress in research on the neurophysiological basis of morphine addiction, American fournal of Psychiatry, 105, 329338.

8. Коов, G. F., Stinus, L., Le Moal, M. \& Bloom, F. E. (1989) Opponent process theory of motivation: neurobiological evidence from studies of opiate dependence, Neuroscience Biobehavioral Reviews, 13, 135-140.

9. Коов, G. F., Caine, S. B., Parsons, L., Markou, A. \& Weiss, F. (1997) Opponent process model and psychostimulant addiction, Pharmacology, Biochemistry and Behavior, 57, 513-521. 
10. Коов, G. F. \& Le Moal, M. (1997) Drug abuse: hedonic homeostatic dysregulation, Science, 278, 52-58.

11. Коов, G. F. (1997) Neurochemical explanations for addiction, Hospital Practice, April, 12-14.

12. Goudie, A. J. \& Demellweek, C. (1986) Conditioning factors in drug tolerance, in: Goldberg, S. R. \& Stolerman, I. P. (Eds) Behavioral Analysis of Drug Dependence, pp. 225285 (New York, Academic Press).

13. Goudie, A. J. (1990) Conditioned opponent processes in the development of tolerance to psychoactive drugs, Progress in NeuroPsychopharmacology and Biological Psychiatry, 14, 675-688.

14. JAFFE, J. H. (1992) Current concepts of addiction, in: O'Brien, C. P. \& Jaffe, J. H. (Eds) Addictive States, pp. 1-21 (New York, Raven Press).

15. Wise, R. A. \& Bozarth, M. A. (1987) A psychomotor stimulant theory of addiction, Psychological Review, 94, 469-492.

16. Shaham, Y., Rajabi, H. \& Stewart, J. (1996) Relapse to heroin-seeking in rats under opioid maintenance: the effects of stress, heroin priming and withdrawal, fournal of Neuroscience, 16, 1957-1963.

17. Stewart, J. \& Wise, R. A. (1992) Reinstatement of heroin self-administration habits: morphine prompts and naltrexone discourages renewed responding after extinction, Psychopharmacology, 108, 79-84.

18. O'BRIEN, C. P. (1997) A range of research-based pharmacotherapies for addiction, Science, 278, 66-70.

19. BerRidge, K. C. \& Robinson, T. E. (1998) What is the role of dopamine in reward: hedonic impact, reward learning, or incentive salience? Brain Research Reviews, 28, 309-369.

20. Skinner, B. F. (1953) Science and Human Behavior (New York, The Free Press).

21. Dews, P. (1977) Remarks, in: Thompson, T. \& Unna, K. R. (Eds) Predicting Dependence Liability of Stimulant and Depressant Drugs, pp. 75-79 (Baltimore, University Park Press).

22. Fischman, M. W. (1989) Relationship between self-reported drug effects and their reinforcing effects: studies with stimulant drugs, NIDA Research Monographs, 92, 211-230.

23. Fischman, M. W., Foltin, R. W., Nestadt, G. \& Pearlson, G. D. (1990) Effects of desipramine maintenance on cocaine self-administration by humans, Fournal of Pharmacology and Experimental Therapeutics, 253, 760-770.

24. Fischman, M. W. \& Foltin, R. W. (1992) Selfadministration of cocaine by humans: a laboratory perspective, in: Bock, G. R. \& WhELAN, J. (Eds.) Cocaine: scientific and social dimensions. CIBA Foundation Symposium No. 166, pp. 165-180 (Chichester, UK, Wiley).

25. Foltin, R. W. \& Fischman, M. W. (1991) Assessment of abuse liability of stimulant drugs in humans: a methodological survey, Drug and Alcohol Dependence, 28, 3-48.
26. Haney, M., Foltin, R. W. \& Fischman, M. W. (1998) Effects of pergolide on intravenous cocaine self-administration in men and women, Psychopharmacology, 137, 15-24.

27. Haney, M., Collins, E. D., Ward, A. S., Foltin, R. W. \& Fischman, M. W. (1999) Effect of a selective dopamine D1 agonist (ABT431) on smoked cocaine self-administration in humans, Psychopharmacology, 143, 102-110.

28. Comer, S. D., Collins, E. D., MacArther, R. B. \& Fischman, M. W. (1999) Comparison of intravenous and intranasal heroin selfadministration by morphine-maintaine d humans, Psychopharmacology, 143, 327-338.

29. Lamb, R. J., Preston, K. L., Schindler, C. W., Meisch, R. A., Davis, F., Katz, J. L., HenningFIELd, J. E. \& Goldberg, S. R. (1991) The reinforcing and subjective effects of morphine in post-addicts: a dose-response study, fournal of Pharmacology and Experimental Therapeutics, 259, 1165-1173.

30. Berridge, K. C. \& Robinson, T. E. (1995) The mind of an addicted brain: neural sensitization of wanting versus liking, Current Directions in Psychological Science, 4, 71-76.

31. Berridge, K. C., Venier, I. L. \& Robinson, T. E. (1989) Taste reactivity analysis of 6-hydroxydopamine-induced aphagia: implications for arousal and anhedonia hypotheses of dopamine function, Behavioral Neuroscience, 103, 36-45.

32. Berridge, K. C. \& Valenstein, E. S. (1991) What psychological process mediates feeding evoked by electrical stimulation of the lateral hypothalamus? Behavioral Neuroscience, 105, 314.

33. BerRidge, K. C. (1996) Food reward: brain substrates of wanting and liking, Neuroscience Biobehavioral Reviews, 20, 1-25.

34. Robinson, T. E. \& Becker, J. B. (1986) Enduring changes in brain and behavior produced by chronic amphetamine administration: a review and evaluation of animal models of amphetamine psychosis, Brain Research Reviews, 11, 157-198.

35. Segal, D. S., Geyer, M. A. \& Schuckit, M. A. (1981) Stimulant-induced psychosis: an evaluation of animal models, Essays in Neurochemistry and Neuropharmacology, 5, 95-129.

36. Stewart, J. \& Badiani, A. (1993) Tolerance and sensitization to the behavioral effects of drugs, Behavioral Pharmacology, 4, 289-312.

37. Broadbent, J. \& Harless, W. E. (1999) Differential effects of $\mathrm{GABA}(\mathrm{A})$ and $\mathrm{GABA}(\mathrm{B})$ agonists on sensitization to the locomotor stimulant effects of ethanol in $\mathrm{DBA} / 2 \mathrm{~J}$ mice, Psychopharmacology, 141, 197-205.

38. Crabbe, J. C., Johnson, N. A., Gray, D. K., Kosobud, A. \& Young, E. R. (1982) Biphasic effects of ethanol on open-field activity: sensitivity and tolerance in $\mathrm{C} 57 \mathrm{BL} / 6 \mathrm{~N}$ and $\mathrm{DBA} / 2 \mathrm{~N}$ mice, Fournal of Comparative and Physiological Psychology, 96, 440-451.

39. Cunningham, C. L. \& Noble, D. (1992) Conditioned activation induced by ethanol: role in sensitization and conditioned place preference, 
Pharmacology Biochemistry and Behavior, 43, 307313.

40. Itzhak, Y. \& MARTin, J. L. (1999) Effects of cocaine, nicotine, dizocipline and alcohol on mice locomotor activity: cocaine-alcohol crosssensitization involves upregulation of striatal dopamine transporter binding sites, Brain Research, 818, 204-211.

41. Lessov, C. N. \& Phillips, T. J. (1998) Duration of sensitization to the locomotor stimulant effects of ethanol in mice, Psychopharmacology, 135, 374-382.

42. Masur, J. \& Boerngen, R. (1980) The excitatory component of ethanol in mice: a chronic study, Pharmacology Biochemistry and Behavior, 13, 777-780.

43. Masur, J., Oliveira de Souza, M. L. \& Zwicker, A. P. (1986) The excitatory effect of ethanol: absence in rats, no tolerance and increased sensitivity in mice, Pharmacology, Biochemistry and Behavior, 24, 1225-1228.

44. Phillips, T. J., Roberts, A. J. \& Lessov, C. N. (1997) Behavioral sensitization to ethanol: genetics and the effects of stress, Pharmacology, Biochemistry and Behavior, 57, 487-493.

45. Manley, S. J. \& Little, H. J. (1997) Enhancement of amphetamine- and cocaine-induced locomotor activity after chronic ethanol administration, fournal of Pharmacology and Experimental Therapeutics, 281, 1330-1339.

46. Nestby, P., Vanderschuren, L. J., De Vries, T. J., Hogenboom, F., Wardeh, G., Mulder, A. H. \& Schoffelmeer, A. N. (1997) Ethanol, like psychostimulants and morphine, causes longlasting hyperreactivity of dopamine and acetylcholine neurons of rat nucleus accumbens: possible role in behavioural sensitization, Psychopharmacology, 133, 69-76.

47. Fahlke, C., Hansen, S., Engel, J. A. \& Hard, E. (1994) Effects of ventral striatal 6-OHDA lesions or amphetamine sensitization on ethanol consumption in the rat, Pharmacology, Biochemistry and Behavior, 47, 345-349.

48. Hunt, W. A. \& Lands, W. E. (1992) A role for behavioral sensitization in uncontrolled ethanol intake, Alcohol, 9, 327-328.

49. Newlin, D. B. \& Thomson, J. B. (1991) Chronic tolerance and sensitization to alcohol in sons of alcoholics, Alcohol: Clinical and Experimental Research, 15, 399-405.

50. White, F. J., Амiт, J., Koeltzow, T. E. \& Hu, X.-T. (1998) Dopamine receptor antagonists fail to prevent induction of cocaine sensitization, Neuropsychopharmacology, 18, 26-40.

51. Browman, K. E., Badiani, A. \& Robinson, T. E. (1998) The influence of environment on the induction of sensitization to the psychomotor activating effects of intravenous cocaine in rats is dose-dependent, Psychopharmacology, 137, 9098.

52. Browman, K. E., Badiani, A. \& Robinson, T. E. (1998) Modulatory effect of environmental stimuli on the susceptibility to amphetamine sensitization: a dose-effect study in rats, fournal of
Pharmacology and Experimental Therapeutics, 287, 1007-1014.

53. Antelman, S. (1988) Time-dependent sensitization as the cornerstone for a new approach to pharmacotherapy: drugs as foreign/stressful stimuli, Drug Development Research, 14, 1-30.

54. Paulson, P. E., Camp, D. M. \& Robinson, T. E. (1991) The time course of transient behavioral depression and persistent behavioral sensitization in relation to regional brain monoamine concentrations during amphetamine withdrawal in rats, Psychopharmacology, 103, 480-492.

55. Henry, D. J. \& White, F. J. (1995) The persistence of behavioral sensitization to cocaine parallels enhanced inhibition of nucleus accumbens neurons, fournal of Neuroscience, 15, 6287-6299.

56. Robinson, T. E. (1988) Stimulant drugs and stress: factors influencing individual differences in the susceptibility to sensitization, in: KaLIVAS, P. W. \& BARNES, C. (Eds) Sensitization of the Nervous System, pp. 145-173 (Caldwell, NJ, Telford Press).

57. White, F. J. \& Wolf, M. E. (1991) Psychomotor stimulants, in: PRATT, J. (Ed.) The Biological Bases of Drug Tolerance and Dependence, pp. 153197 (New York, Academic Press).

58. Hooks, M. S., Duffy, P., Striplin, C. \& Kalivas, P. W. (1994) Behavioral and neurochemical sensitization following cocaine selfadministration, Psychopharmacology, 115, 265272 .

59. Marinelli, M., Le Moal, M. \& Piazza, P. V. (1998) Sensitization to the motor effects of contingent infusions of heroin but not of kappa agonist RU 51599, Psychopharmacology, 139, 281-285.

60. Phillips, A. G. \& Di Ciano, P. (1996) Behavioral sensitization is induced by intravenous selfadministration of cocaine by rats, Psychopharmacology, 124, 279-281.

61. Glick, S. D., Shapiro, R. M., Drew, K. L., Hinds, P. A. \& Carlson, J. N. (1986) Differences in spontaneous and amphetamine-induced rotational behavior, and in sensitization to amphetamine, among Sprague-Dawley derived rats from different sources, Physiology and Behavior, 38, 67-70.

62. Leith, N. J. \& Kuczenski, R. (1982) Two dissociable components of behavioral sensitization following repeated amphetamine administration, Psychopharmacology, 76, 310-315.

63. Shuster, L., Yu, G. \& Bates, A. (1977) Sensitization to cocaine stimulation in mice, Psychopharmacology, 52, 185-190.

64. Glick, S. D. \& Hinds, P. A. (1984) Sex differences in sensitization to cocaine-induced rotation, European fournal of Pharmacology, 99, 119-121.

65. Post, R. M. \& Contel, N. R. (1983) Human and animal studies of cocaine: implications for development of behavioral pathology, in: Creese, I. (Ed.) Stimulants: neurochemical, behavioral and clinical perspectives, pp. 169-203 (New York, Raven Press). 
66. Robinson, T. E. (1984) Behavioral sensitization: characterization of enduring changes in rotational behavior produced by intermittent injections of amphetamine in male and female rats, Psychopharmacology, 84, 466-475.

67. CAmp, D. M. \& Robinson, T. E. (1988) Susceptibility to sensitization. II. The influence of gonadal hormones on enduring changes in brain monoamines and behavior produced by the repeated administration of D-amphetamine or restraint stress, Behavioural Brain Research, 30, 69-88.

68. Antelman, S. M., Eichler, A. J., Black, C. A. \& KocAN, D. (1980) Interchangeability of stress and amphetamine in sensitization, Science, 207, 329-331.

69. Cunningham, C. L. (1995) Localization of genes influencing ethanol-induced conditioned place preference and locomotor activity in BXD recombinant inbred mice, Psychopharmacology, 120, 28-41.

70. Phillips, T. J., Huson, M., Gwiazdon, C., Burkhart-Kasch, S. \& Shen, E. H. (1995) Effects of acute and repeated ethanol exposures on the locomotor activity of BXD recombinant inbred mice, Alcohol: Clinical Experimental Research, 19, 269-278.

71. Tolliver, B. K., Belknap, J. K., Woods, W. E. \& CARNEY, J. M. (1994) Genetic analysis of sensitization and tolerance to cocaine, fournal of Pharmacology and Experimental Therapeutics, 270, 1230-1238.

72. Robinson, T. E., Browman, K. E., Crombag, H. S. \& Badiani, A. (1998) Modulation of the induction or expression of psychostimulant sensitization by the circumstances surrounding drug administration, Neuroscience Biobehavioral Reviews, 22, 347-354.

73. Anagnostaras, S. G. \& Robinson, T. E. (1996) Sensitization to the psychomotor stimulant effects of amphetamine: modulation by associative learning, Behavioral Neuroscience, 110, 13971414.

74. Pert, A., Post, R. \& Weiss, S. R. (1990) Conditioning as a critical determinant of sensitization induced by psychomotor stimulants, NIDA Research Monograph, 97, 208-241.

75. Post, R. M., Lockfeld, A., Seuillace, K. M. \& Contel, N. R. (1981) Drug-environment interaction: context dependency of cocaine-induced behavioral sensitization, Life Sciences, 28, 755760 .

76. Terelli, E. \& Terry, P. (1999) Amphetamineinduced conditioned activity and sensitization: the role of habituation to the test context and the involvement of Pavlovian processes, Behavioral Pharmacology, 9, 409-419.

77. Castañeda, E., Becker, J. B. \& Robinson, T. E. (1988) The long-term effects of repeated amphetamine treatment in vivo on amphetamine, $\mathrm{KCl}$ and electrical stimulation evoked striatal dopamine release in vitro, Life Sciences, 42, 24472456.

78. Henry, D. J. \& White, F. J. (1991) Repeated cocaine administration causes persistent enhancement of D1 dopamine receptor sensitivity within the rat nucleus accumbens, fournal of Pharmacology and Experimental Therapeutics, 258, 882-890.

79. Kantor, L., Hewlett, G. H. \& Gnegy, M. E. (1999) Enhanced amphetamine- and $\mathrm{K}+$-mediated dopamine release in rat striatum after repeated amphetamine: differential requirements for $\mathrm{Ca} 2+-$ and calmodulin-dependent phosphorylation and synaptic vesicles, fournal of Neuroscience, 19, 3801-3808.

80. Robinson, T. E. \& Becker, J. B. (1982) Behavioral sensitization is accompanied by an enhancement in amphetamine-stimulated dopamine release from striatal tissue in vitro, European Fournal of Pharmacology, 85, 253-254.

81. VANDERschuren, L. J., Wardeh, G., De VRIES, T. J., Mulder, A. H. \& Schoffelmeer, A. N. (1999) Opposing role of dopamine D1 and D2 receptors in modulation of rat nucleus accumbens noradrenaline release, fournal of Neuroscience, 19, 4123-4131.

82. Badiani, A., Anagnostaras, S. G. \& Robinson, T. E. (1995) The development of sensitization to the psychomotor stimulant effects of amphetamine is enhanced in a novel environment, Psychopharmacology, 117, 443-452.

83. Badiani, A., Browman, K. E. \& Robinson, T. E. (1995) Influence of novel versus home environments on sensitization to the psychomotor stimulant effects of cocaine and amphetamine, Brain Research, 674, 291-298.

84. Badiani, A., Camp, D. M. \& Robinson, T. E. (1997) Enduring enhancement of amphetamine sensitization by drug-associated environmental stimuli, Fournal of Pharmacology and Experimental Therapeutics, 282, 787-794.

85. Crombag, H. C., Mueller, H., Browman, K. E., Badiani, A. \& Robinson, T. E. (1999) A comparison of two behavioral measures of psychomotor activation following intravenous amphetamine or cocaine: dose- and sensitizationdependent changes, Behavioural Pharmacology, 10, 205-213.

86. Fraioli, S., Crombag, H. S., Badiani, A. \& Robinson, T. E. (1999) Susceptibility to amphetamine-induced locomotor sensitization is modulated by environmental stimuli, Neuropsychopharmacology, 20, 533-541.

87. Badiani, A., Oates, M. M., Day, H. E. W., Watson, S. J., Akil, H. \& Robinson, T. E. (1998) Amphetamine-induced behavior, dopamine release, and c-fos mRNA expression: modulation by environmental novelty, fournal of Neuroscience, 18, 10579-10593.

88. Badiani, A., Oates, M. M., Day, H. E. W., Watson, S. J., Akil, H. \& Robinson, T. E. (1999) Environmental modulation of amphetamine-induced c-fos expression in D1 versus D2 striatal neurons, Behavioural Brain Research, 103, 203-209.

89. Schenk, S. \& Partridge, B. (1997) Sensitization and tolerance in psychostimulant self- 
administration, Pharmacology,Biochememistry and Behavior, 57, 543-550.

90. Horger, B. A., Shelton, K. \& Schenk, S. (1990) Preexposure sensitizes rats to the rewarding effects of cocaine, Pharmacology Biochemistry and Behavior, 37, 707-711.

91. Horger, B. A., Giles, M. K. \& Schenk, S. (1992) Preexposure to amphetamine and nicotine predisposes rats to self-administer a low dose of cocaine, Psychopharmacology, 107, 271276.

92. Piazza, P. V., Deminière, J. M., Le Moal, M. \& SIMON, H. (1989) Factors that predict individual vulnerability to amphetamine self-administration, Science, 245, 1511-1513.

93. Piazza, P. V., Deminière, J. M., Le Moal, M. \& Simon, H. (1990) Stress- and pharmacologicallyinduced behavioral sensitization increases vulnerability to acquisition of amphetamine self-administration, Brain Research, 514, 22-26.

94. Pierre, P. J. \& Vezina, P. (1997) Predisposition to self-administer amphetamine: the contribution of response to novelty and prior exposure to the drug, Psychopharmacology (Berlin), 129, 277284.

95. Pierre, P. J. \& Vezina, P. (1998) D1 dopamine receptor blockade prevents the facilitation of amphetamine self-administration induced by prior exposure to the drug, Psychopharmacology, 138, 159-166.

96. Valadez, A. \& Schenk, S. (1994) Persistence of the ability of amphetamine preexposure to facilitate acquisition of cocaine self-administration, Pharmacology, Biochemistry and Behavior, 47, 203-205.

97. Woolverton, W. L., Goldberg, L. I. \& Ginos, J. Z. (1984) Intravenous self-administration of dopamine receptor agonists by rhesus monkeys, Fournal of Pharmacology and Experimental Therapeutics, 230, 678-683.

98. Gaiardi, M., Bartoletti, M., Bacchi, A., Gubellini, C., Costa, M. \& Babbini, M. (1991) Role of repeated exposure to morphine in determining its affective properties: place and taste conditioning studies in rats, Psychopharmacology, 103, 183-186.

99. Lett, B. T. (1989) Repeated exposures intensify rather than diminish the rewarding effects of amphetamine, morphine, and cocaine, Psychopharmacology, 98, 357-362.

100. Shippenberg, T. S. \& Heidbreder, C. (1995) Sensitization to the conditioned rewarding effects of cocaine: pharmacological and temporal characteristics, Fournal of Pharmacology and Experimental Therapeutics, 273, 808-815.

101. Shippenberg, T. S., Heidbreder, C. \& Lefevour, A. (1996) Sensitization to the conditioned rewarding effects of morphine: pharmacology and temporal characteristics, European Fournal of Pharmacology, 299, 33-39.

102. Shippenberg, T. S., Lefevour, A. \& HeIdbreder, C. (1996) k-opioid receptor agonists prevent sensitization to the conditioned rewarding effects of cocaine, Fournal of Pharma- cology and Experimental Therapeutics, 276, 545554.

103. Lorrain, D. S., Arnold, G. M. \& Vezina, P. (2000) Previous exposure to amphetamine increases incentive to obtain the drug: long-lasting effects revealed by the progressive ratio schedule. Behavioural Brain Research, 107, 9-19.

104. Mendrek, A., Blaha, C. D. \& Phillips, A. G. (1998) Pre-exposure of rats to amphetamine sensitizes self-administration of this drug under a progressive ratio schedule, Psychopharmacology, 135, 416-422.

105. TAylor, J. R. \& Horger, B. A. (1999) Enhanced responding for conditioned reward produced by intra-accumbens amphetamine is potentiated after cocaine sensitization, Psychopharmacology, $142,31-40$.

106. Deroche, V., Le Moal, M. \& Piazza, P. V. (1999) Cocaine self-administration increases the incentive motivational properties of the drug in rats, European Fournal of Neuroscience, 11, 27312736 .

107. De Vries, T. J., Schoffelmeer, A. N. M., Mulder, A. H. \& VANDERSChuren, L. J. M. J. (1997) Reinstatement of drug-seeking behavior following long-term extinction of cocaine and heroin self-administration: possible role of behavioral sensitization, Society for Neuroscience Abstracts, 23, 2147.

108. De Vries, T. J., Schoffelmeer, A. N., Binnekade, R., Mulder, A. H. \& VanderSCHUREN, L. J. (1998) Drug-induced reinstatement of heroin- and cocaine-seeking behaviour following long-term extinction is associated with expression of behavioural sensitization, European Fournal of Neuroscience, 10, 3565-3571.

109. De Vries, T. J., Schoffelmeer, A. N. M., Binnekade, R. \& VANDERSChuren, L. J. M. J. (1999) Dopaminergic mechanisms mediating the incentive to seek cocaine and heroin following long-term withdrawal of IV drug selfadministration, Psychopharmacology, 143, 254260.

110. VAnderschuren, L. J. M. J., Schoffelmeer, A. N. M., Mulder, A. H. \& De Vries, T. J. (1999) Dopaminergic mechanisms mediating the longterm expression of locomotor sensitization following pre-exposure to morphine or amphetamine, Psychopharmacology, 143, 244253.

111. Mitchell, J. B. \& Stewart, J. (1990) Facilitation of sexual behaviors in the male rat associated with intra-VTA injections of opiates, Pharmacology, Biochemistry and Behavior, 35, 643-650.

112. Fiorino, D. F. \& Phillips, A. G. (1999) Facilitation of sexual behavior in male rats following d-amphetamine-induced behavioral sensitization, Psychopharmacology, 142, 200-208.

113. Fiorino, D. F. \& Phillips, A. G. (1999) Facilitation of sexual behavior and enhanced dopamine efflux in the nucleus accumbens of male rats after D-amphetamine-induced behavioral sensitization, Fournal of Neuroscience, 19, 456-463.

114. Washton, A. M. \& Stone-Washton, N. (1993) 
Outpatient treatment of cocaine and crack addiction: a clinical perspective, NIDA Research Monographs, 135, 15-30.

115. Harmer, C. J., Hitchcott, P. K., Morutto, S. L. \& Phillips, G. D. (1997) Repeated damphetamine enhances stimulated mesoamygdaloid dopamine transmission, Psychopharmacology, 132, 247-254.

116. Harmer, C. J. \& Phillips, G. D. (1999) Enhanced dopamine efflux in the amygdala by a predictive, but not a non- predictive, stimulus: facilitation by prior repeated D-amphetamine, Neuroscience, 90, 119-130.

117. Harmer, C. J. \& Phillips, G. D. (1999) Enhanced conditioned inhibition following repeated pretreatment with d-amphetamine, Psychopharmacology, 142, 120-131.

118. Harmer, C. J. \& Phillips, G. D. (1998) Enhanced appetitive conditioning following repeated pretreatment with d-amphetamine, Behavioral Pharmacology, 9, 299-308.

119. Robinson, T. E., Jurson, P. A., Bennett, J. A. \& Bentgen, K. M. (1988) Persistent sensitization of dopamine neurotransmission in ventral striatum (nucleus accumbens) produced by past experience with $(+)$-amphetamine: a microdialysis study in freely moving rats, Brain Research, 462, 211-222.

120. Robbins, T. W. \& Everitt, B. J. (1996) Neurobehavioural mechanisms of reward and motivation, Current Opinions in Neurobiology, 6, 228-236.

121. Kalivas, P. W. \& Stewart, J. (1991) Dopamine transmission in the initiation and expression of drug- and stress-induced sensitization of motor activity, Brain Research Reviews, 16, 223-244.

122. Pierce, R. C. \& Kalivas, P. W. (1997) A circuitry model of the expression of behavioral sensitization to amphetamine-like psychostimulants, Brain Research Reviews, 25, 192-216.

123. White, F. J. \& Kalivas, P. W. (1998) Neuroadaptations involved in amphetamine and cocaine addiction, Drug and Alcohol Dependence, 51, 141153.

124. Wolf, M. E. (1998) The role of excitatory amino acids in behavioral sensitization to psychomotor stimulants, Progress in Neurobiology, 54, 679-720.

125. SMith, G. P. (1995) Dopamine and food reward, in: Morrison, A. M. \& Fluharty, S. J. (Eds) Progress in Psychobiology and Physiological Psychology, pp. 83-144 (New York).

126. Wise, R. A. \& Rompre, P.-P. (1989) Brain dopamine and reward, Annual Review of Psychology, 40, 191-225.

127. White, F. J., Hu, X. T., Zhang, X. F. \& Wolf, M.E. (1995) Repeated administration of cocaine or amphetamine alters neuronal responses to glutamate in the mesoaccumbens dopamine system, Fournal of Pharmacology and Experimental Therapeutics, 273, 445-454.

128. Robinson, T. E. \& Kolb, B. (1997) Persistent structural modifications in nucleus accumbens and prefrontal cortex neurons produced by previous experience with amphetamine, fournal of Neuroscience, 17, 8491-8497.
129. Robinson, T. E. \& Kolb, B. (1999) Alterations in the morphology of dendrites and dendritic spines in the nucleus accumbens and prefrontal cortex following repeated treatment with amphetamine or cocaine, European Fournal of Neuroscience, 11, 1598-1604.

130. Flores, C., Rodaros, D. \& Stewart, J. (1998) Long-lasting induction of astrocytic basic fibroblast growth factor by repeated injections of amphetamine: blockade by concurrent treatment with a glutamate antagonist, fournal of Neuroscience, 18, 9547-9555.

131. Flores, C.. Samaha, A-N. \& Stewart, J. S. (2000) Requirement of endogenous basic fibroblast growth factor for sensitization to amphetamine, fournal of Neuroscience, 20 RC55, 1-5.

132. Horger, B. A., Iyasere, C. A., Berhow, M. T. et al. (1999) Enhancement of locomotor activity and conditioned reward to cocaine by brainderived neurotrophic factor, Fournal of Neuroscience, 19, 4110-4122.

133. ANGrist, B. (1994) Amphetamine psychosis: clinical variations of the syndrome, in: $\mathrm{CHO}, \mathrm{A} . \mathrm{K}$. \& SEgAL, D. S. (Eds) Amphetamine and its Analogs: psychopharmacology, toxicology and abuse, pp. 387414 (New York, Academic Press).

134. Sato, M., Chen, C. C., Akiyama, K. \& Otsuki, S. (1983) Acute exacerbation of paranoid psychotic state after long-term abstinence in patients with previous methamphetamine psychosis, Biological Psychiatry, 18, 429-440.

135. Sato, M. (1986) Acute exacerbation of methamphetamine psychosis and lasting dopaminergic upersensitivity - a clinical survey, Psychopharmacology Bulletin, 22, 751-756.

136. Segal, D. S. \& Schuckit, M. A. (1983) Animal models of stimulant-induced psychosis, in: Creese, I. (Ed.) Stimulants: Neurochemical, Behavioral and Clinical Perspectives, pp. 131-167 (New York, Raven Press).

137. Utena, H. (1966) Behavioral aberrations in methamphetamine-intoxicated animals and chemical correlates in the brain, in: Tokizane, $\mathrm{T}$. \& Schade, J. P. (Eds) Progress in Brain Research, Vol. 21B, Coerrelative neurosciences: clinical studies, pp. 192-207 (Amsterdam, Elsevier).

138. Castner, S. A. \& Goldman-Rakic, P. S. (1999) Long-lasting psychotomimetic consequences of repeated low-dose amphetamine exposure in rhesus monkeys, Neuropsychopharmacology, 20, 1028.

139. Strakowski, S. M., Sax, K. W., Setters, M. J. \& KECK, P. E., JR (1996) Enhanced response to repeated d-amphetamine challenge: evidence for behavioral sensitization in humans, Biological Psychiatry, 40, 872-880.

140. Strakowski, S. M. \& Sax, K. W. (1998) Progressive behavioral response to repeated $\mathrm{d}$ amphetamine challenge: further evidence for sensitization in humans, Biological Psychiatry, 44, 1171-1177.

141. Strakowski, S. M., Rosenberg, H. L., DelBello, M. P. \& SAX, K. W. (1999) Behavioral sensitization in humans: results of a parallel- 
group, double-blind study, Abstracts, American College of Neuropsychopharmacology, 38, 86.

142. Rothman, R. B., Gorelick, D. A., Baumann, M. H., Guo, X. Y., Herning, R. I., Pickworth, W. B., Gendron, T. M., Koeppl, B., Thomson, L. E. \& Henningfield, J. E. (1994) Lack of evidence for context-dependent cocaine-induced sensitization in humans: preliminary studies, Pharmacology, Biochemistry and Behavior, 49, 583-588.

143. Gorelick, D. A. \& Rothman, R. B. (1997) Stimulant sensitization in humans, Biological Psychiatry, 42, 230-231.

144. Strakowski, S. M., SAx, K. W., Setters, M. J. \& KECK, P. E., JR (1997) Stimulant sensitization in humans-response, Biological Psychiatry, 42, 230-231.

145. Bartlett, E., Hallin, A., Chapman, B. \& ANGRIST, B. (1997) Selective sensitization to the psychosis-inducing effects of cocaine: a possible marker for addiction relapse vulnerability? Neuropsychopharmacology, 16, 77-82.

146. Breiter, H. C., Gollub, R. L., Weisskoff, R. M., Kennedy, D. N., Makris, N., Berke, J. D., Goodman, J. M., Kantor, H. L., Gastfriend, D. R., Riorden, J. P., Mathew, R. T., Rosen, B. R. \& Hyman, S. E. (1997) Acute effects of cocaine on human brain activity and emotion, Neuron, 19, 591-611.

147. Childress, A. R., Mozley, P. D., McElgin, W., Fitzgerald, J., Reivich, M. \& O'Brien, C. P. (1999) Limbic activation during cue-induced cocaine craving, American fournal of Psychiatry, 156, 11-18.

148. Grant, S., London, E. D., Newlin, D. B., Villemagne, V. L., LiU, X., Contoreggi, C., Phillips, R. L., Kimes, A. S. \& Margolin, A. (1996) Activation of memory circuits during cue-elicited cocaine craving, Proceedings of the National Academy Sciences USA, 93, 1204012045.

149. MaAs, L. C., Lukas, S. E., Kaufman, M. J., Weiss, R. D., Daniels, S. L., Rogers, V. W., Kukes, T. J. \& Renshaw, P. F. (1998) Functional magnetic resonance imaging of human brain activation during cue-induced cocaine craving, American Fournal of Psychiatry, 155, 124126.

150. Wang, G. J., Volkow, N. D., Fowler, J. S., Cervany, P., Hitzemann, R. J., Pappas, N. R., Wong, C. T. \& Felder, C. (1999) Regional brain metabolic activation during craving elicited by recall of previous drug experiences, Life Sciences, 64, 775-784.

151. Sell, L. A., Morris, J., Bearn, J., Frackowiak, R. S., Friston, K. J. \& Dolan, R. J. (1999) Activation of reward circuitry in human opiate addicts, European fournal of Neuroscience, 11, 1042-1048.

152. Kaufman, M. J., Levin, J. M., Maas, L. C., Rose, S. L., Lukas, S. E., Mendelson, J. H., Cohen, B. M. \& Renshaw, P. F. (1998) Cocaine decreases relative cerebral blood volume in humans: a dynamic susceptibility contrast magnetic resonance imaging study, Psychopharmacology, $138,76-81$

153. Gonon, F. \& Sundstrom, L. (1996) Excitatory effects of dopamine released by impulse flow in the rat nucleus accumbens in vivo, Neuroscience, $75,13-18$.

154. Gonon, F. (1997) Prolonged and extrasynaptic excitatory action of dopamine mediated by D1 receptors in the rat striatum in vivo, fournal of Neuroscience, 17, 5972-5978.

155. Berridge, K. C. (1999) Pleasure, pain, desire and dread: hidden core processes of emotion, in: Kahneman, D., Diener, E. \& Schwarz, N. (Eds) Well Being: the foundations of hedonic psychology, pp. 527-559 (New York, Russell Sage Foundation).

156. Wise, R. A. (1982) Neuroleptics and operant behavior: the anhedonia hypothesis, Behavioral and Brain Sciences, 5, 39-87.

157. Gardner, E. L. \& Lowinson, J. H. (1993) Drug craving and positive/negative hedonic brain substrates activated by addicting drugs, Seminars in Neuroscience, 5, 359-368.

158. WisE, R. A. (1994) A brief history of the anhedonia hypothesis, in: LegG, C. R. \& Booth, D. (Eds) Appetite: neural and behavioral bases, pp. 140-319 (New York, Oxford University Press).

159. Nash, M. J. (1997) Addicted: why do people get hooked? Mounting evidence points to a powerful brain chemical called dopamine, Time, May 5, 68-76.

160. WiCKelgren, I. (1997) Getting the brain's attention, Science, 278, 35-37.

161. Markou, A. \& Koob, G. F. (1991) Postcocaine anhedonia: an animal model of cocaine withdrawal, Neuropsychopharmacology, 4, 17-26.

162. Rossetti, Z. L., Hmaidan, Y. \& Gessa, G. L. (1992) Marked inhibition of mesolimbic dopamine release: a common feature of ethanol, morphine, cocaine and amphetamine abstinence in rats, European Fournal of Pharmacology, 221, 227-234.

163. Volkow, N. D., Wang, G. J., Fowler, J. S., Logan, J., Gatley, S. J., Hitzemann, R., Chen, A. D., Dewey, S. L. \& Pappas, N. (1997) Decreased striatal dopaminergic responsiveness in detoxified cocaine-dependent subjects, Nature, 386, 830-833.

164. Weiss, F., Markou, A., Lorang, M. T. \& Коов, G. F. (1992) Basal extracellular dopamine levels in the nucleus accumbens are decreased during cocaine withdrawal after unlimited-access selfadministration, Brain Research, 593, 314-318.

165. Markou, A., Kosten, T. R. \& Koob, G. R. (1998) Neurobiological similarities in depression and drug dependence: a self-medication hypothesis, Neuropsychopharmacology, 135-174.

166. Di Chiara, G. \& TANDA, G. (1997) Blunting of reactivity of dopamine transmission to palatable food: a biochemical marker of anhedonia in the CMS model? Psychopharmacology, 134, 351-353; discussion 371-377.

167. Volkow, N. D., Wang, G. J., Fischman, M. W., 
Foltin, R. W., Fowler, J. S., Abumrad, N. N., Vitkun, S., Logan, J., Gatley, S. J., Pappas, N., Hitzemann, R. \& Shea, C. E. (1997) Relationship between subjective effects of cocaine and dopamine transporter occupancy, Nature, 386, 827-830.

168. Анmed, S. H. \& Коов, G. F. (1998) Transition from moderate to excessive drug intake: change in hedonic set point, Science, 282, 298-300.

169. Blackburn, J. R., Pfaus, J. G. \& Phillips, A. G. (1992) Dopamine functions in appetitive and defensive behaviours, Progress in Neurobiology, 39, 247-279.

170. Pecina, S., Berridge, K. C. \& Parker, L. A. (1997) Pimozide does not shift palatability: separation of anhedonia from sensorimotor suppression by taste reactivity, Pharmacology, Biochemistry and Behavior, 58, 801-811.

171. Schultz, W. (1992) Activity of dopamine neurons in the behaving primate, Seminars in Neuroscience, 4, 129-138.

172. Schultz, W. (1998) Predictive reward signal of dopamine neurons, fournal of Neurophysiology, $80,1-27$.

173. Salamone, J. D., Cousins, M. S. \& Snyder, B. J. (1997) Behavioral functions of nucleus accumbens dopamine: empirical and conceptual problems with the anhedonia hypothesis, Neuroscience Biobehavioral Reviews, 21, 341-359.

174. Berger, S. P., Hall, S., Mickalian, J. D., Reid, M. S., Crawford, C. A., Delucchi, K., Carr, K. \& HaLL, S. (1996) Haloperidol antagonism of cue-elicited cocaine craving, Lancet, 347, 504508.

175. Brauer, L. H. \& DeWit, H. (1996) Subjective responses to d-amphetamine alone and after pimozide pretreatment in normal, healthy volunteers, Biological Psychiatry, 39, 26-32.

176. Brauer, L. H. \& DeWiT, H. (1997) High dose pimozide does not block amphetamine-induced euphoria in normal volunteers, Pharmacology, Biochemistry and Behavior, 56, 265-272.

177. Ohuoha, D. C., Maxwell, J. A., Thomson, L. E. III, Cadet, J. L. \& Rothman, R. B. (1997) Effect of dopamine receptor antagonists on cocaine subjective effects: a naturalistic case study, Fournal of Substance Abuse Treatment, 14, 249258.

178. Rothman, R. B. \& Glowa, J. R. (1995) A review of the effects of dopaminergic agents on humans, animals, and drug-seeking behavior, and its implications for medication development. Focus on GBR 12909, Molecular Neurobiology, 11, 119.

179. Volkow, N. D., Wang, G. J., Fowler, J. S., Gatley, S. J., Logan, J., Ding, Y. S., Dewey, S. L., Hitzemann, R., Gifford, A. N. \& Pappas, N. R. (1999) Blockade of striatal dopamine transporters by intravenous methylphenidate is not sufficient to induce self-reports of "high", fournal of Pharmacology and Experimental Therapeutics, 288, 14-20.

180. BINDRA, D. (1978) How adaptive behavior is produced: a perceptual-motivation alternative to response reinforcement, Behavioral and Brain Sciences, 1, 41-91.

181. Toates, F. (1986) Motivational Systems (Cambridge, Cambridge University Press).

182. Tiffany, S. T. (1990) A cognitive model of drug urges and drug-use behavior: role of automatic and nonautomatic processes, Psychological Review, 97, 147-168.

183. Weiskrantz, L. (1997) Consciousness Lost and Found: a neuropsychological exploration (New York, Oxford University Press).

184. Hilgard, E. R. (1986) Divided Consciousness: multiple controls in human thought and action (New York, John Wiley and Sons).

185. LeDoux, J. (1996) The Emotional Brain: the mysterious underpinnings of emotional life (New York, Simon and Schuster).

186. Nisbett, R. E. \& Wilson, T. D. (1977) Telling more than we can know: verbal reports on mental processes, Psychological Review, 84, 231-259.

187. Kahneman, D. (1994) New challenges to the rationality assumption, fournal of Institutional and Theoretical Economics, 150, 18-36.

188. Loewenstein, G. (1999) A visceral account of addiction, in: Elster, J. \& Skog, J. (Eds.) Getting Hooked: rationality and addiction, pp. 235-264 (Cambridge, Cambridge University Press).

189. Sarter, M. \& Bruno, J. P. (1999) Abnormal regulation of corticopetal cholinergic neurons and impaired information processing in neuropsychiatric disorders, Trends in Neuroscience, 22, 67-74.

190. Jentsch, J. D. \& Taylor, J. R. (1999) Impulsivity resulting from frontostriatal dysfunction in drug abuse: implications for the control of behavior by reward-related stimuli, Psychopharmacology, 146, 373-390.

191. Bolla, K. I., Cadet, J. L. \& London, E. D. (1998) The neuropsychiatry of chronic cocaine abuse, Fournal of Neuropsychiatry and Clinical Neuroscience, 10, 280-289.

192. Rogers, R. D., Everitt, B. J., Baldacchino, A., Blackshaw, A. J., Swainson, R., Wynne, K., Baker, N. B., Hunter, J., Carthy, T., Booker, E., London, M., Deakin, J. F., Sahakian, B. J. \& Robbins, T. W. (1999) Dissociable deficits in the decision-making cognition of chronic amphetamine abusers, opiate abusers, patients with focal damage to prefrontal cortex, and tryptophan-depleted normal volunteers: evidence for monoaminergic mechanisms, Neuropsychopharmacology, 20, 322-339.

193. Biggins, C. A., MacKay, S., Clark, W. \& Fein, G. (1997) Event-related potential evidence for frontal cortex effects of chronic cocaine dependence, Biological Psychiatry, 42, 472-485.

194. Volkow, N. D., Fowler, J. S., Wolf, A. P., Hitzemann, R., Dewey, S., Bendriem, B., Alpert, R. \& HoFf, A. (1991) Changes in brain glucose metabolism in cocaine dependence and withdrawal, American fournal of Psychiatry, 148, 621-626.

195. Volkow, N. D., Hitzemann, R., Wang, G. J., Fowler, J. S., Wolf, A. P., Dewey, S. L. \& 
HANDLESMAN, L. (1992) Long-term frontal brain metabolic changes in cocaine abusers, Synapse, 11, 184-190.

196. Steele, C. M. \& Josephs, R. A. (1990) Alcohol myopia, American Psychologist, 45, 921-933.

197. Meyer, R. E. (1992) New pharmacotherapies for cocaine dependence ... revisited [published erratum appears in Archives of General Psychiatry 1993, 50(1),16], Archives of General Psychiatry, 49, 900-904.

198. Galloway, G. P., Newmeyer, J., Knapp, T., STAlCUP, S. A. \& SMITH, D. (1996) A controlled trial of imipramine for the treatment of methamphetamine dependence, Fournal of Substance Abuse Treatment, 13, 493-497.

199. Nunes, E. V., McGrath, P. J., Quitkin, F. M., OcepeK-Welikson, K., Stewart, J. W., Koenig, T., Wager, S. \& KLEIN, D. F. (1995) Imipramine treatment of cocaine abuse: possible boundaries of efficacy, Drug and Alcohol Dependence, 39, $185-195$.

200. WeIss, R. D. (1988) Relapse to cocaine abuse after initiating desipramine treatment, Fournal of the American Medical Association, 260, 25452546.

201. Nomikos, G. G., Damsma, G., Wenkstern, D. \& Fibiger, H. C. (1991) Chronic desipramine enhances amphetamine-induced increases in interstitial concentrations of dopamine in the nucleus accumbens, European fournal of Pharmacology, 195, 63-73.

202. Goldstein, M. G. (1998) Bupropion sustained release and smoking cessation, fournal of Clinical Psychiatry, 59, 66-72.

203. Jorenby, D. E., Leischow, S. J., Nides, M. A., Rennard, S. I., Johnston, J. A., Hughes, A. R., Smith, S. S., Muramoto, M. L., Daughton, D. M., Doan, K., Fiore, M. C. \& Baker, T. B. (1999) A controlled trial of sustained-release bupropion, a nicotine patch, or both for smoking cessation, New England fournal of Medicine, 340, 685-691.

204. Cooper, B. R., Wang, C. M., Cox, R. F., Norton, R., Shea, V. \& Ferris, R. M. (1994) Evidence that the acute behavioral and electrophysiological effects of bupropion (Wellbutrin) are mediated by a noradrenergic mechanism, Neuropsychopharmacology, 11, 133-141.

205. Petrie, E. C., Veith, R. C. \& Szot, P. (1998) Bupropion and desipramine increase dopamine transporter mRNA expression in the ventral tegmental area/substantia nigra of rat brain, Progress in Neuropsychopharmacology and Biological Psychiatry, 22, 845-856.

206. Tella, S. R., Ladenheim, B. \& Cadet, J. L. (1997) Differential regulation of dopamine transporter after chronic self- administration of bupropion and nomifensine, Fournal of Pharmacology and Experimental Therapeutics, 281, 508-513.
207. Little, K. Y., Zhang, L., Desmond, T., Frey, K. A., Dalack, G. W. \& Cassin, B. J. (1999) Striatal dopaminergic abnormalities in human cocaine users, American fournal of Psychiatry, 156, 238-245.

208. Zhang, L., Elmer, L. W. \& Little, K. Y. (1998) Expression and regulation of the human dopamine transporter in a neuronal cell line [published erratum appears in 1998 Dec 10, 63(1), 205], Molecular Brain Research, 59, 66-73.

209. Nomikos, G. G., Damsma, G., Wenkstern, D. \& Fibiger, H. C. (1992) Effects of chronic bupropion on interstitial concentrations of dopamine in rat nucleus accumbens and striatum, Neuropsychopharmacology, 7, 7-14.

210. al Qatari, M., Bouchenafa, O. \& Littleton, J. (1998) Mechanism of action of acamprosate. Part II. Ethanol dependence modifies effects of acamprosate on NMDA receptor binding in membranes from rat cerebral cortex, Alcohol Clinical and Experimental Research, 22, 810-814.

211. NaAssila, M., Hammoumi, S., Legrand, E., Durbin, P. \& Daoust, M. (1998) Mechanism of action of acamprosate. Part I. Characterization of spermidine-sensitive acamprosate binding site in rat brain, Alcohol: Clinical and Experimental Research, 22, 802-809.

212. Besson, J., Aeby, F., Kasas, A., Lehert, P. \& Potgieter, A. (1998) Combined efficacy of acamprosate and disulfiram in the treatment of alcoholism: a controlled study, Alcohol: Clinical and Experimental Research, 22, 573-579.

213. Kratzer, U. \& SchmidT, W. J. (1998) The anticraving drug acamprosate inhibits the conditioned place aversion induced by naloxone-precipitated morphine withdrawal in rats, Neuroscience Letters, 252, 53-56.

214. Putzke, J., Spanagel, R., Tolle, T. R. \& ZIEGLGANSBERGER, W. (1996) The anti-craving drug acamprosate reduces c-fos expression in rats undergoing ethanol withdrawal, European fournal of Pharmacology, 317, 39-48.

215. Blackburn, J. R. \& Szumlinski, K. K. (1997) Ibogaine effects on sweet preference and amphetamine induced locomotion: implications for drug addiction, Behavioural Brain Research, 89, 99-106.

216. Jackson, A., Mead, A. N., Rocha, B. A. \& STephens, D. N. (1998) AMPA receptors and motivation for drug: effect of the selective antagonist NBQX on behavioural sensitization and on self-administration in mice, Behavioral Pharmacology, 9, 457-467.

217. Mead, A. N. \& Stephens, D. N. (1998) AMPAreceptors are involved in the expression of amphetamine-induced behavioural sensitisation, but not in the expression of amphetamine- induced conditioned activity in mice, Neuropharmacology, 37, 1131-1138. 